\title{
A census of Meddies in a long-term high-resolution simulation
}

\author{
Ana Cláudia Barbosa Aguiar ${ }^{a, *}$, Álvaro Peliz $^{\mathrm{b}}$, Xavier Carton $^{\mathrm{c}}$
}

\author{
${ }^{a}$ Centro de Oceanografia, Faculdade de Ciências, Universidade de Lisboa, Campo Grande, 1749-016 Lisboa, \\ Portugal \\ b Instituto Dom Luiz, Faculdade de Ciências, Universidade de Lisboa, Campo Grande, 1749-016 Lisboa, Portugal \\ ${ }^{c}$ Laboratoire de Physique des Ocèans, UMR6523 CNRS/IFREMER/UBO, UFR Sciences, Brest, France \\ *: Corresponding author : Ana Cláudia Barbosa Aguiar, email address : aaaguiar@fc.ul.pt
}

\begin{abstract}
:
The output from a high-resolution two-decade long Mediterranean Outflow simulation is analysed here to provide a census of Mediterranean Water eddies (aka Meddies), both anticyclones and cyclones. The formation rate of Meddies that survive for at least 90 days is of 12 Meddies $\mathrm{yr}^{-1}$ of which $\sim 12 \%$ are cyclones. The rate of formation reaches 40 Meddies $\mathrm{yr}^{-1}$ ( $30 \%$ cyclones) when considering all the Meddies living over 15 days. About $70 \%$ of the population is born along the southwestern lberian slope, but several robust Meddies also originate in points of convergence of the main pathways into the open ocean. The longest-lived Meddies propagate northwestwards, but most of the anticyclones veer southwestwards after a while. As the Meddies drift away from their birthplace, their radius tends to increase gradually from 15 to $30 \mathrm{~km}$. The thickness (depth-difference between isopycnals 27.2 and 27.5) of anticyclones born near Cape St. Vincent contracts by approximately $100 \mathrm{~m}$, after travelling $1000 \mathrm{~km}$ from their source; their mean swirl velocities range from about $21 \mathrm{~cm} \mathrm{~s}^{-1}$ (at $z=1000 \mathrm{~m}$ ) up to $27 \mathrm{~cm} \mathrm{~s}^{-1}$ (at $z=600 \mathrm{~m}$ ). Mean salinity and temperature anomalies are significantly lower for cyclones, which in general are also more slowly rotating, shallower and thinner than anticyclones. Cyclones are more easily tracked at $600 \mathrm{~m}$ depth where longer trajectories are recorded. In the vicinity of Portimão Canyon, cyclones outnumber anticyclones while the reverse happens downstream of Cape St. Vincent.
\end{abstract}

\section{Highlights}

40 (12) Meddies/yr, 30\% (12\%) cyclones, living a minimum of 15 (90) days $-30 \%$ of Meddies originate far from the slope in convergence points of main pathways Asymmetric distribution of anticyclones/cyclones with respect to Cape St. Vincent - Long-lived Meddies propagate NW; cyclones more easily tracked at $600 \mathrm{~m}$ - Meddies' radius increases and thickness contracts as they move away from slope 
Mediterranean Water, Mesoscale modelling

\section{Introduction}

Through the Strait of Gibraltar, warm and salty waters from the Mediterranean Sea spread into the North Atlantic ocean, flowing as a density current at intermediate depths along the southern Iberian slope. The Mediterranean Outflow is partitioned in two main cores: the Upper Core at depths between 600 and $1000 \mathrm{~m}$ and the Lower Core at depths between 1000 and $1300 \mathrm{~m}$ (Ambar et al., 2008, e.g.). Occasionally, it is also possible to discern a Shallow Core at depths between 400 and $600 \mathrm{~m}$ (Ambar, 1983, e.g.) and another denser and deeper branch known as the Deep Core. The latter is confined to a bottom trapped vein (1300-1600 m) found in the vicinity of Portimão Canyon (e.g. Bower et al. (2002); Ambar et al. (2008)).

A strong salinity anomaly in the 600-1500 m depth range exists in a more or less triangular region, the Mediterranean salt tongue, based on the western Iberian Peninsula shelf. This feature dominates the thermohaline structure of the Northeastern Atlantic. The shape of this feature coincides roughly with the distribution of sub-surface vortices that carry Mediterranean Water (MW) away into the open ocean. Indeed, the circulation in the Mediterranean salt tongue is dominated by advection and diffusion processes.

The vast majority of the observed Meddies are anticyclones and usually only anticyclones are referred to as Meddies. However, several observations revealed the existence of cyclonic eddies containing MW and estimated to account for about $30 \%$ of the population (Richardson et al., 2000). Henceforth, both types of eddies will be uniquely referred to as Meddies. These are characterised by a central core region with strong temperature and salinity anomalies and in approximate solid body rotation. Typical radii range from $10 \mathrm{~km}$ (Bower et al., 1997) to $60 \mathrm{~km}$ (Richardson and Tychensky, 1998) and the larger ones are usually older too. While anticyclones exhibit a core that can extend from $500 \mathrm{~m}$ down to $1500 \mathrm{~m}$, cyclones tend to be shallower vortices with their core centered at about $600 \mathrm{~m}$ (Carton et al., 2002). Such aspect ratio gives them a flattened, lens-like three-dimensional shape. For both eddy polarities, records indicate maximum swirl velocities of $30 \mathrm{~cm}$ $\mathrm{s}^{-1}$ near the central depth of the core. Nevertheless, the velocity field of these structures usually extends over a large portion of the water column, further than their thermohaline anomalous core. They are sensitive to sharp 
changes in topography which helps to steer them but may also trigger their disruption.

Mediterranean Water lenses are largely formed by instability of the Mediterranean Outflow, but they may also originate by interaction of MW filaments with seamounts, currents or surface-intensified eddies. There are several hypothesis of generation processes and the details are not totally clear. These include separation of a frictional boundary layer (D'Asaro, 1988; Bower et al., 1997), topographic or coastal effects such as those of capes (Pichevin and Nof, 1996; Chérubin et al., 2000; Serra et al., 2002; Serra and Ambar, 2002; Serra et al., 2005) and baroclinic instability of a density current (Chérubin et al., 2007; Duarte et al., 2011). Estimates of the rates of formation near Cape St. Vincent and Estremadura Promontory (see Figure 1) are of 10 and 7 Meddies per year, respectively (Bower et al., 1997). More recent studies (Carton et al., 2002; Ambar et al., 2008; Carton et al., 2010) have identified Meddies in the Gulf of Cadiz, concluding that Meddies will also frequently detach from the Mediterranean Outflow near the Portimão Canyon. Demidov et al. (2012) suggest a figure of 20-25 lenses per year, for generation over the whole Iberian Coast - the highest guess among the literature.

These vortices are believed to play a significant role in sustaining the aforementioned Mediterranean Salt tongue and have been the subject of several studies (mostly in situ) over the last three decades, e.g. Richardson et al. (1989); Bower et al. (1997); Richardson et al. (2000); Ambar et al. (2008); Demidov et al. (2012). However, the available data are rather sparse in space and time, rendering it difficult to weigh in their total contribution towards the salinification of the North Atlantic.

Efforts have been made to model the formation of Meddies, using either idealised simulations (Aiki and Yamagata, 2004, e.g.) or more realistic models at regional and global scales (Jungclaus and Mellor, 2000; Serra et al., 2005; Drillet et al., 2005). These studies attained promising results but were hampered by either the reduced size of domain or low resolution, short period of simulation, and not very accurate boundary conditions at the Strait of Gibraltar. For instance, in Drillet et al. (2005) the Meddies simulated tend to be colder and fresher, and 15\% are larger than reported by observations.

Here, the Mediterranean Outflow is reproduced numerically in the best possible way given the forceful parametrization of mixing processes at small scales. Atmospheric forcing is included. The highest realism is achieved after using the most suitable boundary conditions at the Strait of Gibraltar. The latter were supplied by another numerical study focused in the exchanges 
between the Mediterranean Sea and the Atlantic (Peliz et al., 2013). The simulation analysed here has a spatial resolution of about $3 \mathrm{~km}$ and covers a period of 20 years, allowing for a thorough study of the population of Meddies.

\section{Model Description}

\subsection{The Ocean Model, Domain and Configuration}

The simulations were performed using the Regional Ocean Modeling System (ROMS), which is a community model designed for regional realistic applications (Shchepetkin and McWilliams, 2005). ROMS kernel is a 3D free-surface, sigma-coordinate, split-explicit primitive equation model with Boussinesq and hydrostatic approximations. ROMS has been extensively used in many regional applications including the Gulf of Cadiz (Peliz et al., 2007, 2009, 2013).

The model's grid (Figure 1) has a $\sim 3 \mathrm{~km}$ horizontal spacing that is $\sim 1 / 3$ of the radius of the smallest Meddies which are thus properly resolved. To ensure a reasonable resolution near the bottom, which is important for an adequate simulation of the outflow on the Gulf of Cadiz slope, the grid has 32 sigma vertical levels with a moderate surface stretching of $\theta_{s}=4\left(\theta_{b}=0\right)$; see Shchepetkin and McWilliams (2005) and Hedström (2009) appendix B for a detailed description of ROMS vertical coordinates. An alternative way of increasing the near-bottom resolution is to use $\theta_{b} \neq 0$. However, the latter would increase the steepness of the sigma layers and, consequently, increase the pressure gradient errors (Shchepetkin and McWilliams, 2003). The baroclinic time-step $\delta t$ is $300 \mathrm{~s}$, and the fast barotropic mode is $\delta t / 40 \mathrm{~s}$.

\subsection{Boundary Conditions}

The open boundary conditions consist of a combination of radiation and flow-adaptive nudging toward prescribed values from climatology as described in Marchesiello et al. (2001). Monthly climatologies of temperature and salinity, together with geostrophic and Ekman velocities (calculated from monthly averaged stratification and surface winds) are used on the boundary as passive/active conditions (Marchesiello et al., 2001). Nudging to climatological values is made with different coefficients for inward (1 day for momentum and 10 days for tracers)/outward flow (360 days for tracers and momentum). Across the nudging/sponge band, the nudging progressively decays to zero in the interior within a band of $50 \mathrm{~km}$ also used for the sponge (see below 
Section 2.3). The initial and open boundary temperature and salinity fields were taken from the WOA 2005 (Locarnini et al., 2006; Antonov et al., 2006) for the southern, western and northern open boundaries. The eastern open boundary was subjected to a different treatment. In order to force an outflow that is as realistic as possible, the climatology was produced with the output from Peliz et al. (2013).

For the barotropic mode we use Orlansky-type radiative conditions together with volume conservation. ROMS volume conservation condition consists of diagnosing the mass imbalance at each time step (by integrating all the barotropic transport along the domain perimeter). In case of loss of volume, a correction is applied, dividing the excess/deficit by all cells along the open boundaries and forcing this mass out/in as a volume compensation. A correct implementation of this conservation condition, in a domain covering the Atlantic and Mediterranean, requires that this condition is applied to each basin separately. Otherwise, the mass compensation induces unwanted and spurious barotropic fluctuations at the strait that sometimes are well above the observed values. In this configuration, we proceed with the separation of the volume condition as described in Peliz et al. (2013). At each time step the barotropic transport was calculated for the Atlantic side $\left(Q_{A t l}\right)$ and for the Mediterranean $\left(Q_{M e d}\right)$, independently. Next, assuming volume conservation, we force the transport entering/leaving on the Atlantic boundary to be equal to the transport leaving/entering on the open boundary in the Mediterranean side and this transport should equal $Q^{t}$, the net (physical) mass transport through the strait $(\sim 0.05 \mathrm{~Sv})$. This approach ensures volume conservation and the needed sub-inertial barotropic transport across the strait. Internally, the model is free to produce the required baroclinic adjustment (the inflow/outflow) to this external barotropic forcing.

\subsection{Numerical Options and Parametrization of the Strait Processes}

A third-order upstream-biased accurate predictor-corrector - leapfrog/AdamsMoulton - time step algorithm (Shchepetkin and McWilliams, 2005) is used for momentum and tracers. In some circumstances, this tracer advection scheme produces spurious diapycnal mixing (Marchesiello et al., 2009), that may lead to substantial erosion of internal structure in low resolution experiments. In finer resolution simulations, this spurious mixing, although inescapable, is not expected to significantly degrade the thermohaline characteristics despite contributing for smoother thermohaline structures. 
Due to the dispersive properties of the advection equation, the simulations can be conducted with reduced or null explicit mixing. Null mixing is applied everywhere except in the sponge layer, where Laplacian viscosity is used and the coefficient is set to ramp up from zero in the innermost cell to $200 \mathrm{~m}^{2}$ $\mathrm{s}^{-2}$ on the outermost cell. The sponge is as wide as the nudging band.

Vertical mixing processes are parametrised with the non-local K-profile (KPP) boundary layer scheme (Large et al., 1994) implemented for both surface and bottom boundary layers. The vertical diffusion terms are treated with a semi-implicit Crank-Nicholson scheme to avoid time step restrictions, due to large vertical mixing rates in the boundary layers and also in the interior when static stability needs to be restored. A uniform and constant quadratic bottom drag coefficient of $3.5 \times 10^{-3}$ is used.

Since the details of the mixing processes and entrainment of the outflow are not explicitly resolved at these resolutions, a localised spot of increased mixing and diffusion was created out of the Strait. A Smagorinsky mixing coefficient is calculated and it is multiplied by a space sine function which decays radially within a $30 \mathrm{~km}$ zone centered at $\left(35.9^{\circ} \mathrm{N} ; 6.15^{\circ} \mathrm{W}\right)$, and in depth using a function based on a hyperbolic tangent that goes to zero for depths above $200 \mathrm{~m}$. This ensures that the mixing spot is very localised laterally and in depth, and is restricted to the lower western part of the channel $\left(35.9^{\circ} \mathrm{N} ; 6.15^{\circ} \mathrm{W}\right)$.

The flow at the source (Strait) is comparable with observed values (transport, and TS characteristics), hence the realism of the mixing processes can be assessed by comparing the simulated water vein with observations at different distances from the Strait. This comparison is not illustrated here but it has been done in previous studies, see e.g. Peliz et al. (2013) (Figure 8).

\subsection{External Forcing and Topography}

Atmospheric forcing is based on momentum and air-sea fluxes monthly climatologies from COADS (da Silva et al., 1994). No tidal forcing was applied. To build the model topography we used two data bases: the global Smith and Sandwell (1997) topography and a local high resolution map described in Sanz et al. (1991) that covers in detail the Strait of Gibraltar. ROMS requires a significant degree of topography smoothing to avoid steep slopes that induce pressure gradient errors (Shchepetkin and McWilliams, 2003, e.g.). This smoothing is usually performed by filtering the initial topography $(h)$ with a $\log (h)$ based filter (Penven et al., 2008, e.g.), and in very steep regions (as in the Strait) it may substantially degrade the topography. 
An iterative procedure to tackle this problem was developed in Peliz et al. (2013) and is applied to the present configuration as well.

For a significant part of the work, the preparation of the model's initial conditions and fields was conducted using the ROMS tools package (Penven et al., 2008).

Note that this experiment will not have interannual variability and it is done so in order to ensure that its outcome reflects the intrinsic variability of the system alone.

\subsection{Mean Circulation and EKE}

Although the study of the mean circulation is out of the scope of this paper, it is instructive to compare the regional circulation features and the mean Eddy Kinetic Energy with those in previous papers. Figure 2 shows the time-mean velocity field $(u, v)$ and the eddy kinetic energy EKE $=$ $0.5\left(\left\langle(u-<u>)^{2}\right\rangle+\left\langle(v-<v>)^{2}\right\rangle\right)$ at $1000 \mathrm{~m}$ depth.

In the velocity field, it is possible to recognise the Mediterranean Undercurrent (with velocities above $10 \mathrm{~cm} \mathrm{~s}^{-1}$ off Cape St. Vincent), a well pronounced southward flow just west of Gorringe bank $\left(\sim 12.5^{\circ} \mathrm{W}\right)$ and a westward zonal flow at $\sim 37.5^{\circ} \mathrm{N}$, which can also be seen in Bower et al. (2002) (Figure 14c). Features such as the eastern branch of the Azores Current $\left(\sim 34^{\circ} \mathrm{N}\right)$ and the southward recirculation at about $16.5^{\circ} \mathrm{W}, 37-39^{\circ} \mathrm{N}$ resemble those observed in Barbosa Aguiar et al. (2011) (Figure 2). Furthermore, the cyclonic recirculation pattern seen in the Gulf of Cadiz coincides with that already documented in several studies (Peliz et al., 2007; Kida et al., 2008; Lamas et al., 2010).

The larger values of EKE ( $>50 \mathrm{~cm}^{2} \mathrm{~s}^{-2}$ ) are spread out along well known corridors for Meddies: a tongue that veers from Cape St. Vincent into the basin among the Horseshoe seamounts and a zonal band at $\sim 38^{\circ} \mathrm{N}$. There are also less familiar features: a small branch of moderate EKE $~ 35 \mathrm{~cm}^{2}$ $\mathrm{s}^{-2}$ in the Gulf of Cadiz and a striking "shadow region" at about $37^{\circ} \mathrm{N}$, $15-18^{\circ} \mathrm{W}$. The range of values of EKE is in very good agreement with the observational results shown in Bower et al. (2002) (Figure 14d), while the shape and location of the most energetic region are close but not exactly the same.

At $600 \mathrm{~m}$ depth (not shown), the same features prevail in both products, albeit with greater intensity.

Despite the intended transparency of the open boundaries to the propagation of eddies there are still obvious signs of recirculations and rim currents 
within the sponge band, on the western boundary and southwest corner of the domain. Those, however, do not seem to disturb the interior of the domain and thus should not affect the propagation of eddies therein.

The experiment was run for 25 years but only the last 20 years were studied so that the eddy fields analysed correspond to a state of full equilibrium, after transient processes of adjustment. A more or less regular chain of vortices could be observed, travelling from the slope to the western boundary, after the first 5 years of simulation. Time-averaged output fields (surface height, velocity, temperature and salinity) were recorded every 3 days $\left(\delta t_{\text {out }}=3\right)$.

\section{Identification and Selection of Meddies}

The task of analysing eddies in such a large dataset demanded the use of an automatic procedure. To identify and track all the eddies that contained MW (Meddies), we decided to run an existing eddy tracking algorithm followed by a "Meddy verification criteria".

The eddy detection algorithm and its source code were developed by Nencioli et al. (2010). This algorithm has been successfully applied to highresolution numerical products, e.g. Dong et al. (2012). In Appendix A, there is a description of the procedure of eddy identification and tracking.

The algorithm was run separately at $z=600 \mathrm{~m}$ and $z=1000 \mathrm{~m} \mathrm{lev-}$ els because the dynamical signature of cyclones $(\mathrm{C})$ and anticyclones $(\mathrm{AC})$ should be more intense at each of these depths, as described above in Section 1. Therefore, this choice is expected to optimise the detection and tracking of $\mathrm{C}$ at $z=600 \mathrm{~m}$ and $\mathrm{AC}$ at $z=1000 \mathrm{~m}$, and this was confirmed by our results (Section 4.1.2).

After running the eddy tracking algorithm we had to determine which of the detected eddies were Meddies. To do so, we devised a rather simple and flexible criteria based on the depth-averaged salinity anomaly of the eddy's centre as explained in Appendix B. What distinguishes Meddies from other eddies is not only the higher values of salinity but also the higher temperatures in their cores. However, the salinity anomaly is clearer and for the sake of simplicity, the criterion devised here relies solely on the depthaveraged salinity anomaly of the eddies.

Any eddy that retained $\Delta S \geq 0.12 \mathrm{psu}$, over more than half of its lifetime $(\gamma \geq 0.5)$ is considered to be a Meddy. This enabled the detection of 
robust Meddies even if they exhibited fairly weak salinity anomalies for some time (see e.g. AC in Figure B.11).

This apparently low threshold of $\Delta S$ is not comparable with those used for the selection of Meddies in observations because it is not computed in the same way. The characteristic salinity anomaly here is a depth-averaged anomaly of a structure known a priori to be an eddy. Historical datasets of observations (Richardson et al., 1991, e.g.) were produced from collections of hydrographic sections not guaranteed to correspond to eddies, hence the need for rather high thresholds referring to the maximum salinity in the section. Many other observational records were gathered by floats seeded directly into the thermohaline core of Meddies, where the anomaly is bound to be very high. Also, the age and life-time of the Meddies surveyed in situ are usually unknown, but most of these are likely to be rather young Meddies (high salinity anomaly) which have trapped drifters seeded into the Mediterranean Undercurrent.

Our choice of threshold parameters $\Delta S$ and $\Delta t$ is down to a compromise: to avoid the detection of too many spurious eddies (non Meddies), while still able to capture a wide range of Meddies, both weak and strong $\Delta S$ and intensified at different depth levels.

Note that inhere we are considering all the eddies with a MW core and not only the ones originating directly from Mediterranean Outflow instability. Furthermore, this study only concerns the southwestern part of the Iberian Peninsula and therefore all Meddy generation sites outside this region are excluded. Other possible sites of generation are Cape Ortegal and Cape Finisterre or Galicia Bank (Richardson et al., 1991; Paillet et al., 1999), as well as other locations along the western coast of Iberia north of $41^{\circ} \mathrm{N}$.

\section{Results}

For an overview of the data, the Meddies are split into different categories according to their life-time $(\Delta t)$ and degree of salinity anomaly $(\Delta S)$, while ensuring $\gamma \geq 0.5$ for all Meddies. The distinction between datasets of Meddies will be made by referring to the values $\Delta S$ and $\Delta t$ (as well as $r$-parameter and $z$-level) used in the Meddies selection described in Appendix A and Appendix B.

To produce a quantitative analysis, we choose to use the dataset of Meddies with $\Delta t \geq 90$ days and $\Delta S \geq 0.12$ psu (Figure 3 top) because: i) shorter-lived Meddies will not have enough time to mature and are unlikely 
to have a significant impact beyond the vicinity of the Iberian slope, and ii) the percentage of cyclones still amounts to nearly 14\% allowing for a reasonably sized sample of cyclones, unlike what happens for higher thresholds of $\Delta S$ and $\Delta t$.

A whole section is dedicated to Meddies born along the Southwestern Iberian slope because these are more likely to form directly from the Mediterranean Undercurrent.

\subsection{Meddies in the Whole Domain of Study}

\subsubsection{Life-times}

In Figure 3 (top and centre) are shown all the Meddies born within the whole region of study and surviving for at least 90 or 150 days with $\Delta S \geq 0.12$ psu. The overall rate of formation varies between 8 units $\mathrm{yr}^{-1}$ for $\Delta t \geq 150$ days and 12 units $\mathrm{yr}^{-1}$ for $\Delta t \geq 90$ days.

Long lived structures are largely anticyclonic. The percentage of cyclonic Meddies reaches $14 \%$ among Meddies that survive at least three months, but it decreases to $10 \%$ when selecting only Meddies that survive for a minimum of five months. In the whole 20 years of simulation, a maximum of 17 cyclones (detected at $z=600 \mathrm{~m}$ ) survived for at least 150 days with $\Delta S \geq 0.12 \mathrm{psu}$. This suggests that nearly one very long-lived cyclone is born every year, while most of the cyclones formed tend to quickly disappear offshore.

While long-lived anticyclones form in the western slope, long-lived cyclones form in the southern slope.

Several Meddies originate far from the slope, namely in the lee side of the seamounts Josephine and Ampère but also in the Gulf of Cadiz and Tagus Abyssal Plain (Figure 3 top). It should be noted that these structures are very resilient Meddies that can survive for rather long periods of time.

For Meddies with life-times as short as 15 (see Table 4) or 30 days (not

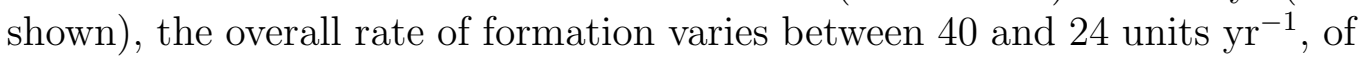
which $30 \%$ and $24 \%$ are cyclones, respectively.

\subsubsection{Sensitivity to Depth Level}

Figure 3 confirms that the success of identification of either type of Meddies is sensitive to the depth levels surveyed. Blue lines (trajectories of $\mathrm{C}$ ) are more numerous at $z=600 \mathrm{~m}$ than at $z=1000 \mathrm{~m}$ (except for $\Delta S \geq 0.3 \mathrm{psu}$ ), and several trajectories are similar in both levels (hence, assumed to correspond to the same eddy) but are significantly longer in the first case. The detection of cyclones is generally more successful at $z=600 \mathrm{~m}$ as expected. 
This confirms the shallower intensification (maximum horizontal velocity) of cyclones versus anticyclones mentioned in Section 1.

On the other hand, for $z=1000 \mathrm{~m}$ and $\Delta S \geq 0.12 \mathrm{psu}$, there are two C-trajectories (finishing in the western border at $36.5^{\circ} \mathrm{N}$ ) which do not match any of the trajectories traced at $z=600 \mathrm{~m}$. The same happens for cyclones with $\Delta S \geq 0.3 \mathrm{psu}$. This is evidence that cyclonic structures can occasionally be intensified at deeper levels too.

\subsubsection{Salinity Anomaly}

The trajectories of Meddies with $\Delta t \geq 90$ days and $\Delta S \geq 0.3 \mathrm{psu}$ are presented in Figure 3 (bottom) and the corresponding rates of formation and percentage of cyclones are in Table 1 , along with rates for $\Delta S \geq 0.12$ and $0.2 \mathrm{psu}$. These threshold values were chosen in order to identify longlived Meddies with strong salinity anomalies, which are likely to be the main carriers of MW to far-off distances.

Only about half of the Meddies that mature to three months or beyond have $\Delta S \geq 0.3 \mathrm{psu}$. A total of 6 units $\mathrm{yr}^{-1}$ were detected at $z=1000 \mathrm{~m}$, of which 3.4 units $\mathrm{yr}^{-1}$ occur in box II, 0.4 unit $\mathrm{yr}^{-1}$ in box I and 0.5 unit $\mathrm{yr}^{-1}$ originate near the Josephine seamount (see limits of boxes in Figure 4). Cyclones seldom verify $\Delta S \geq 0.3 \mathrm{psu}$ and $\Delta t \geq 90$, with only three examples detected at $z=1000 \mathrm{~m}$ and none recorded at $z=600 \mathrm{~m}$ (see Figure 3 bottom).

\subsubsection{Rates of Exit of Meddies into the North Atlantic}

In Table 2 are listed the rates of survival into the North Atlantic (exit of the domain) recorded for different sets of Meddies tracked with $r=18 \mathrm{~km}$. These correspond to all Meddies whose last record lies within $0.2^{\circ}$ of the southernmost, westernmost and northernmost limits considered here. For the Meddies with $\Delta t \geq 90$ days, the rates of survival into open ocean vary between 2.8 and 4.5 units $\mathrm{yr}^{-1}$. The largest percentage of the total eddy population that manages to reach the North Atlantic is about $50 \%$, attained when $\Delta t \geq 90$ days and $\Delta S \geq 0.3 \mathrm{psu}$. The latter indicates that the Meddies which are more likely to reach open ocean are those with the largest salinity anomalies.

\subsubsection{Properties of Meddies in the Whole Domain}

In Table 3 are given the physical characteristics of the Meddies with $\Delta t \geq 90$ days and $\Delta S \geq 0.12 \mathrm{psu}$. Results are presented for each type of 
eddy and level of detection, taking into account the time-mean parameters along each trajectory recorded: $190 \mathrm{AC}$ and $31 \mathrm{C}$ at $z=600 \mathrm{~m}$, and $216 \mathrm{AC}$ and $28 \mathrm{C}$ at $z=1000 \mathrm{~m}$.

From the results in Table 3 it is clear that cyclones are short-lived structures: the results indicate average survival times of only $57-64 \%$ of the average life-time of anticyclones. Similar results are obtained for the respective total distances travelled. Also, at the level $z=600 \mathrm{~m}$, the cyclones can be tracked for longer periods and distances than at $z=1000 \mathrm{~m}$.

The radii of both $\mathrm{AC}$ and $\mathrm{C}$ are comparable: the mean radius of $\mathrm{AC}$ and $\mathrm{C}$ varies between 23 and $27 \mathrm{~km}$, but the largest anticyclone had a radius of $64 \mathrm{~km}$ whereas the largest cyclone had a smaller radius of $50 \mathrm{~km}$.

At both depth-levels analysed, the mean swirl velocities of $\mathrm{C}$ are only about $60 \%$ of those of $\mathrm{AC}$.

For both types of Meddies, the translation velocities are similar and typically about $3 \mathrm{~cm} \mathrm{~s}^{-1}$, with peak values of $5.2-6.2 \mathrm{~cm} \mathrm{~s}^{-1}$ and minima of $1.1-1.7 \mathrm{~cm} \mathrm{~s}^{-1}$. It should be noted that the eddy detection parameter $r=18 \mathrm{~km}$ used here imposes a maximum of $V_{t} \sim 7 \mathrm{~cm} \mathrm{~s}^{-1}$. The analysis of a dataset of Meddies obtained after running the detection with $r=36 \mathrm{~km}$ (maximum $V_{t} \sim 14 \mathrm{~cm} \mathrm{~s}^{-1}$ ) revealed that at most $11 \%$ of the Meddies would exhibit $V_{t} \geq 6.5 \mathrm{~cm} \mathrm{~s}^{-1}$ (not shown).

The salinity and temperature values, as well as the respective anomalies, presented in Table 3 are the vertical average over depths between $600 \mathrm{~m}$ and $1300 \mathrm{~m}$, along the profile of the dynamical eddy's centre detected at either $z=600 \mathrm{~m}$ or $z=1000 \mathrm{~m}$. While the mean salinity values are very close for each type of eddy, the mean salinity anomalies recorded for $\mathrm{C}$ are only about $55 \%$ of those for AC. The mean and maximum values of temperatures in AC are always about $1^{\circ} \mathrm{C}$ degree higher than for $\mathrm{C}$, and the mean temperature anomalies of $\mathrm{AC}\left(\sim 1.3^{\circ} \mathrm{C}\right)$ are also much higher than those of $\mathrm{C}\left(\sim 0.4^{\circ} \mathrm{C}\right)$. In the dataset presented here, the largest depth-averaged time-mean salinity and temperature anomalies of a Meddy were of $0.57 \mathrm{psu}$ and $2.44^{\circ} \mathrm{C}$, respectively, both recorded in Meddies detected at $z=1000 \mathrm{~m}$.

\subsection{Meddies of the Iberian Slope}

\subsubsection{Population, Sites and Rates of Formation}

The trajectories of Meddies born along the southwestern Iberian slope during the 20 years of simulation, and surviving for at least 90 days, are plotted in Figure 4 (top). The hotspots of coastal formation are found upstream and downstream of Cape St. Vincent within boxes I and II, respectively, but 
there is also some formation occurring at Setubal Canyon and Estremadura Promontory in box III. The Meddies formation rate for the three boxes altogether is roughly of 8 units $\mathrm{yr}^{-1}$ for both depth levels analysed. Box II records the highest formation rate with about 6 units $\mathrm{yr}^{-1}$ while in box I this rate is approximately of 1 unit $\mathrm{yr}^{-1}$. When running the eddy detection for $r=36 \mathrm{~km}$ the rates of generation are slightly lower - the results are summarised in Table 4.

The rates of formation are much higher when analysing the Meddies dataset with $\Delta S \geq 0.12 \mathrm{psu}$ and a life-time threshold of only 15 days (see Table 4). Combining the three boxes, the formation rate reaches 18 units $\mathrm{yr}^{-1}$, with about 9 units $\mathrm{yr}^{-1}$ in box II and 5.5 (7.2) units $\mathrm{yr}^{-1}$ in box I, for an eddy detection at $z=600 \mathrm{~m}(z=1000 \mathrm{~m})$.

By comparing the rates of formation for different regions, it becomes clear that a significant amount of Meddies (nearly half, if $\Delta S \geq 0.12 \mathrm{psu}$ and $\Delta t \geq 15$ days) are born far from the Iberian slope as observed in Section 4.1.1.

The percentage of the population of Meddies with cyclonic rotation varies considerably depending on the formation site considered, as shown by the rather asymmetric distribution of blue lines in Figure 4. While all Meddies (except one at $z=600 \mathrm{~m}$ ) in box II have anticyclonic rotation, the reverse happens in box I where cyclonic Meddies account for $57-91 \%$ of the population (see Table 4). When considering all the Meddies born in boxes I, II and III, the percentage of cyclonic vortices is only about $8-14 \%$ if $\Delta t \geq 90$ days, but increases to $27-32 \%$ if $\Delta t \geq 15$ days.

\subsubsection{Main Paths}

The vast majority of slope's Meddies will initially move northwestwards to the Tagus Abyssal Plain from where they can follow two distinct paths: a "highway" between the Horseshoe seamounts and the Estremadura Promontory (at about $38^{\circ} \mathrm{N}$ ) that leads them straight to west, or a "winding path" that leads them southwestward through the Horseshoe seamounts; for topographic references see Figure 1. In the latter case, while some of the Meddies take an exit to west, several others exit to south (where the gaps between the seamounts are wider) and can either turn southwestwards to Madeira Island or continue further south to the Canary Basin with some detours. Right after formation, a minority of Meddies will travel straight to south and may veer eastwards to the Gulf of Cadiz (Figure 4).

Meddies born in box I (mostly $\mathrm{C}$ ) tend to remain in the Gulf of Cadiz throughout their life-time (Figure 4 bottom), but some will also take a 
southward, northwestward, or even a westward (straight into the Horseshoe seamounts) path.

West of $\sim 16^{\circ} \mathrm{W}$, most of the Meddies travelling westward will eventually turn southwestward following a path more or less along the western border of the Horseshoe seamounts to west of Madeira Island. In a few cases, the trajectories just happen to suddenly veer to the south, e.g. partly meridional trajectories of $\mathrm{C}$ and $\mathrm{AC}$ at $\sim 16.5^{\circ} \mathrm{W}$ in Figure $4(z=600 \mathrm{~m})$, probably under the influence of a southward regional current that can be seen in Figure 2 (top). Furthermore, some cyclones continue to travel westwards or northwestwards through the western border of the domain.

By comparing the results for both depth levels surveyed, it is again noticeable (see Section 4.1.2) that cyclones can be followed for a longer time (and distance) when tracked at $z=600 \mathrm{~m}$ - see Figure 4 (top). Also, the percentage of $\mathrm{C}$ detected in box I increases by roughly $20 \%$ when the eddy detection was ran at $z=600 \mathrm{~m}$ instead of $z=1000 \mathrm{~m}$ (see Table 4).

\subsubsection{Evolution of Meddies}

In Figure 5 is presented a comparison between Meddies born in each box of the Iberian Slope and the evolution of their characteristics as they age and move away from their origin. $\mathrm{AC}$ and $\mathrm{C}$ were treated separately and the data were not plotted for samples with less than 10 Meddies. At every point of a trajectory, the curvilinear distance to origin was computed as the sum of the distance between each two previous points. The records of all the Meddies were then binned into segments of $40 \mathrm{~km}$, according to the respective distances to origin, and the mean and standard deviation values were computed for each bin. This analysis was done for both levels of tracking but given the similarities, at the exception of swirl velocity, only the results of tracking at $z=600 \mathrm{~m}$ are shown in Figure 5. The Meddies analysed here correspond to a subset (eddies born in the Iberian Slope) of the Meddies population with $\Delta S \geq 0.12 \mathrm{psu}$ and $\Delta t \geq 90$ analysed in Table 3 .

The first chart provides information on the number of records used, illustrating that the statistical significance of the data is very heterogeneous given the large differences in the number of Meddies of each type per box. Moreover, the number of records tends to decrease as the distance to origin increases. The values provided for AC from box II are the most statistically significant. Halfway to the origin, the number of records is more or less constant at about 500 counts. It peaks at $500 \mathrm{~km}$ and then drops to about 300 counts at $1000 \mathrm{~km}$. In boxes I and III the number of records reaches about 
100 counts.

The radius of the Meddies tends to gradually increase from about $15 \mathrm{~km}$ at birth to values above $25 \mathrm{~km}$ (box II) or $30 \mathrm{~km}$ (box I) by the end of tracking, about $1000 \mathrm{~km}$ away from the source. At $z=600 \mathrm{~m}, \mathrm{C}$ from box I exhibit somewhat larger radii (and standard deviations) than AC from box II, while the reverse happens at $z=1000 \mathrm{~m}$ (not shown).

The thickness $(h)$ of the Meddies was estimated as the difference between the depths of isopycnals 27.2 and 27.5 (with reference to the surface level) along the profile of the eddy's centre. The depth of the maximum of salinity between the same isopycnals $\left(z S_{\max }\right)$, as well as the depth-averaged salinity and temperature anomalies in that depth range $(\langle\delta S\rangle,\langle\delta T\rangle)$ are also represented in Figure 5.

The graphs show that the thickness of cyclones is only about $250-300 \mathrm{~m}$ and more or less constant with distance, whereas the thickness of anticyclones varies from $\sim 450-500 \mathrm{~m}$ at the origin to $\sim 400-430 \mathrm{~m}$ after $1000 \mathrm{~km}$. The depth of the maximum of salinity is always shallower in cyclones $(\sim 600-700$ $\mathrm{m})$ than in anticyclones $(\sim 800-850 \mathrm{~m})$ where this maximum deepens slightly with distance to origin.

Both salinity and temperature anomalies are significantly lower for cyclones than for anticyclones, and the anomalies from Meddies with origin in box II are typically larger than those in box III. As expected, the salinity and temperature anomalies estimated here (see Appendix B) increase steadily as the Meddies progress into the eastern North Atlantic, translating into fresher and colder background waters.

For Meddies of box II the translation velocity $\left(V_{t}\right)$ appears to decrease from 4 to $3 \mathrm{~cm} \mathrm{~s}^{-1}$ at $500 \mathrm{~km}$ away from the origin (perhaps due to topographic obstacles), increasing slightly after that only to drop again to $3 \mathrm{~cm}$ $\mathrm{s}^{-1}$ or below at about $850 \mathrm{~km}$.

At $z=600 \mathrm{~m}$, the swirl velocities $\left(V_{s}\right)$ of AC from box II quickly increase from $\sim 21 \mathrm{~cm} \mathrm{~s}^{-1}$ to $\sim 27 \mathrm{~cm} \mathrm{~s}^{-1}$ within the first $100 \mathrm{~km}$, decreasing monotonously to $\sim 22 \mathrm{~cm} \mathrm{~s}^{-1}$ after that. At $z=1000 \mathrm{~m}$, the swirl velocity increases initially from $\sim 15 \mathrm{~cm} \mathrm{~s}^{-1}$ to $\sim 21 \mathrm{~cm} \mathrm{~s}^{-1}$, staying roughly constant afterward. These speeds are significantly higher than records concerning the other boxes: $\sim 10-20 \mathrm{~cm} \mathrm{~s}^{-1}$ at $z=600 \mathrm{~m}$ and $\sim 6-15 \mathrm{~cm} \mathrm{~s}^{-1}$ at $z=1000$ $\mathrm{m}$.

For illustration purposes only, the mean trajectories (and standard deviation of the coordinates) of the Meddies born along the Iberian slope and tracked at $z=600 \mathrm{~m}$ are plotted in Figure 6. Such schematic highlights 
the main points of origin and directions followed by the slope Meddies, but it lacks the variety of noticeable bends and routes visible in the spaghetti diagrams of Figure 4.

\section{Summary of Simulated Meddies}

1. Initially, most of the Meddies move northwestwards but then either propagate straight to west or veer southwestward facing a winding path across the Horseshoe seamounts. West of $16^{\circ} \mathrm{W}$ most of the Meddies turn southwestwards, probably due to the regional currents and the effect of local topography. A few Meddies recirculate in the Gulf of Cadiz.

2. The longest-lived cyclones propagate northwestwards passing between Josephine and Tore seamounts, never veering southwards. Shorter-lived cyclones either recirculate in the Gulf of Cadiz or travel northwestwards into the Tagus Abyssal Plain. Few cyclones move southwestwards to the Horseshoe seamounts.

3. In the whole domain of study, the rate of formation reaches 40 Meddies $\mathrm{yr}^{-1}$ considering all the Meddies that survived for at least 15 days and whose salinity anomaly value was above $0.12 \mathrm{psu}$, the lowest value that still classifies the simulated eddies as Meddies. About 30\% of the population of Meddies are cyclones. When restricting the analysis to the southwestern Iberian slope, the formation rate is almost halved to 18 Meddies $\mathrm{yr}^{-1}$. The rate of generation around Portimão Canyon varies between 5.5 Meddies $\mathrm{yr}^{-1}(z=600 \mathrm{~m})$ and 7.2 Meddies $\mathrm{yr}^{-1}$ $(z=1000 \mathrm{~m})$, being dominated by cyclonic Meddies $(84 \%$ and $61 \%$ in each case). The upper rates near Cape St. Vincent and Estremadura Promontory are respectively of 9.3 Meddies $\mathrm{yr}^{-1}$ and 1.4 Meddies $\mathrm{yr}^{-1}$ (see Table 4). Note that such a low threshold on the life-time increases the likelihood of counting the same event more than once. Every time the Meddy fails to fulfil the detection criteria only to fulfil it again afterward (more than 6 days later) it will be considered a new event.

4. When considering only Meddies that survived for at least 90 days, with minimum salinity anomalies of 0.12 or $0.3 \mathrm{psu}$, the rates of formation drop to about 12 or 6 Meddies $\mathrm{yr}^{-1}$ respectively, while the percentage of cyclonic Meddies decreases to $12 \%$ or $3 \%$, in the whole domain of study. Several robust Meddies originate on the lee side of Josephine seamount and fewer on Gorringe, Ampère and Lion seamounts. 
5. As the Meddies drift away from their birthplace, their radius tends to increase gradually from 15 to $30 \mathrm{~km}$. After travelling about $1000 \mathrm{~km}$ away from its origin, a Meddy's thickness contracts by approximately $100 \mathrm{~m}$. The Meddies that form near Cape St. Vincent have mean swirl velocities that range from about $21 \mathrm{~cm} \mathrm{~s}^{-1}$ (at $z=1000 \mathrm{~m}$ ) up to $\sim 27$ $\mathrm{cm} \mathrm{s}^{-1}$ (at $z=600 \mathrm{~m}$ ). These velocities are larger than those of Meddies forming around Estremadura Promontory or Portimão Canyon, and the same happens for salinity and temperature anomalies.

6. Cyclones are more easily tracked at $600 \mathrm{~m}$, where longer trajectories are recorded. Mean salinity and temperature anomalies are significantly lower for cyclones, which in general are also more slowly rotating, shallower and thinner than anticyclones. The thickness of cyclones $(\sim 250$ $\mathrm{m}$ ) remains more or less constant throughout their trajectories, unlike the radius that tends to increase slightly.

7. In general, the population of Meddies born in the vicinity of Portimão Canyon is distinct: cyclonic Meddies outnumber anticyclones (minimum salinity anomalies of $0.12 \mathrm{psu}$ ) and the few cyclones exhibiting the salinity anomalies above $0.3 \mathrm{psu}$ can only be tracked at depth $(1000$ $\mathrm{m})$. However, a comparison of physical properties of Meddies formed upstream and downstream of Cape St. Vincent provided ambiguous results.

\section{Discussion}

\subsection{Formation and Main Paths of Meddies}

Several sites of formation of Meddies have been identified here: Portimão Canyon, Cape St. Vincent, Estremadura Promontory and the lee-side of several Horseshoe seamounts. Two different snapshots of vorticity and salinity fields at $z=1000 \mathrm{~m}$ are shown in Figures 7 and 9 to illustrate an instant of the spatial distribution of MW lenses. Note the prominent string of vortices off Cape St. Vincent in Figure 7. The main paths chosen by Meddies coincide with regions of enhanced EKE (Figure 2 bottom) due to the stirring effects of Meddies (Bower et al., 2002).

Although Portimão Canyon has only been confirmed as a source of Meddies in the last 10 years (Serra and Ambar, 2002; Carton et al., 2002; Serra et al., 2005), Cape St. Vincent and Estremadura Promontory have been recognized as such since Zenk et al. (1992) and Bower et al. (1997). There is prevalence of similarly shaped trajectories of both anticyclones and cyclones 
in the Gulf of Cadiz and the formation of a dipole is evident in Figure 8. In that figure, two poles of positive and negative vorticity correspond to two relative maxima of salinity. This confirms the hypothesis of dipole-generation off the Portimão Canyon already discussed by several authors (Serra and Ambar, 2002; Ambar et al., 2008; Carton et al., 2010). However, dipole structures are not exclusive to the southern Iberian slope and can be seen elsewhere, e.g. in Figure 9 there is another dipole forming off Estremadura Promontory.

Beforehand, the only seamount reported to be another birth place of Meddies was Gorringe bank (Serra and Ambar, 2002). Our results indicate three new generation sites: seamounts Josephine, Lion and Ampère. These new hotspots of formation coincide with convergence points of the major pathways described in Section 4.2.2, hence it is likely that the origin of Meddies here is due to merging or "re-birth" of previous ones.

The latter possibility is exemplified in Figure 10: two weeks after a Meddy ended its life on the stoss side of Josephine, a new Meddy is born on the lee side of the same seamount. The original Meddy arrives from northeast, shedding vorticity and salinity as it moves clockwise around the seamount due to the local topographic $\beta$-effect. During the interaction with the seamount, the Meddy signal is lost on day $06 / 24$ as it is weakened beyond possible detection. However, after one complete revolution the filaments of vorticity are reinforced and reorganised into a new core that is able to detach from the southern edge of Josephine. Note that the salinity in the core of the newly formed Meddy (detected from the day 07/06 onwards) is lower than in the previous one. Peculiar interactions of Meddies with seamounts have been reported in literature (Richardson and Tychensky, 1998) and addressed by idealised experiments (Cenedese, 2002). Figure 10 is merely illustrative and the occurrence of merging and re-birth of Meddies will be carefully studied in future work.

The more common pathways described here correspond to the ones previously known: near the eastern boundary Meddies will drift northwards or northwestwards, while offshore Meddies tend to move westwards and southwestwards (Richardson et al., 2000) reaching as far as the area south of the Azores Islands and the Canary Basin (Richardson and Tychensky, 1998). However, it is seen here that some Meddies will instead: i) translate southwards right after their formation, occasionally recirculating into the Gulf of Cadiz, or ii) veer to west with a very small deviation to south, straight after formation in the Tagus Abyssal Plain or after an initial northwards drift 
off Cape St. Vincent. Furthermore, the former Meddies will occasionally spend some of their life-time near the Moroccan shelf, as first brought to attention by the observations of Carton et al. (2002) and corroborated by the recent sighting of a Meddy at about $12.5^{\circ} \mathrm{W}, 31.5^{\circ} \mathrm{N}$ (Ménesguen et al., 2012). These results show that cyclones tend to linger in the Gulf of Cadiz or else (fewer ones) take a distinct path towards northwest. The presence of so many cyclones in the Gulf of Cadiz is not entirely surprising and is supported by observational evidence (Carton et al., 2002; Ambar et al., 2008). To our knowledge, the possibility of having cyclones taking such a long northwestward path since the Portimão Canyon is a new result.

In past literature, the full picture of Meddies pathways just described is closest to that presented by Shapiro and Meschanov (1996) (their Figure 8) when referring to the main spreading paths of MW in the Iberian Basin.

Based on observations from drifters, the rate of formation of Meddies is expected to be between 8-12 per year (Richardson et al., 1989) and 15-20 per year (Bower et al., 1997). These two estimates are based on observations of Meddies far from and in the vicinity the Iberian slope, respectively. By adding the formation rates in the boxes containing the Portimão Canyon, Cape St. Vincent and Estremadura Promontory, our results indicate that between 8 and 18 Meddies are born every year along the southwestern Iberian slope and survive for at least 90 and 15 days, respectively; these are in very good agreement with observational estimates. In the region of Cape St. Vincent alone, the upper rate of formation of 9.3 Meddies $\mathrm{yr}^{-1}$ is very close to the estimated 10 events per year based on data from drifters (Bower et al., 1997; Ambar et al., 2008). However, the number of events detected in the Estremadura Promontory is much lower than the estimate of $7-10$ events per year by Bower et al. (1997); Ambar et al. (2008). The latter could be due to three reasons: i) the flow in this region is affected by its proximity to the border of the domain, ii) the criteria for Meddies selection are too strict for Meddies forming this far downstream, where the characteristics of MW are expected to be more diluted, and iii) the Meddies' generation requires the maintenance of a slope current (along the southwestern margin) that may not be well reproduced in the model at such large distance from the Strait of Gibraltar.

Among the Meddies living more than 15 days, cyclones account for 28$31 \%$ of the population which comes very close to the $1: 3$ ratio (C:AC) anticipated by Richardson et al. (2000).

Considering the whole domain of study, there are about 12 events per 
year of Meddies living more than 90 days. Nearly $40 \%$ of these (4.5 Meddies $\mathrm{yr}^{-1}$ ) succeed in exiting the domain, carrying away a significant portion of MW to the west and south, far into the North Atlantic.

Another important result from the present study is that long-lived Meddies correspond to no more than $40 \%$ of the total of Meddies generated (see Table 4). The fate of short-lived Meddies should be investigated: is their disappearance due to merging or destruction? Perhaps merging is a key process for the survival of Meddies.

\subsection{Properties of Meddies}

The maximal time-mean radius of $50-60 \mathrm{~km}$ presented here are supported by records of floats. Some floats have described loops around $120 \mathrm{~km}$ in diameter while trapped in Meddies far from the slope (Richardson and Tychensky, 1998; Richardson et al., 2000).

Our results indicate that Meddies are about $50 \mathrm{~km}$ wide on average. No major differences on the dynamical radius (where the velocity magnitude is maximum, $\left.R_{v \max }\right)$ of anticyclones and cyclones were detected. The radius computed here is slightly shorter than the dynamical radius and the dynamical radius itself is shorter than the thermohaline core of the Meddies. For a vortex with a Gaussian profile of radial velocity, the radius under the influence of the eddy's velocity is approximately $R_{0} \simeq \sqrt{2} R_{\text {vmax }}$ (Carton et al., 2002).

If some Meddies are formed by separation of a frictional boundary layer from the coast (D'Asaro, 1988), then the radius of young Meddies should be about $10 \mathrm{~km}$ which is the estimated width of the anticyclonic shear zone of the Mediterranean undercurrent (Bower et al., 1997). On the light of this theory and of some observations (Bower et al., 1997; Serra and Ambar, 2002), the minimum time-mean radii of $10-15 \mathrm{~km}$ computed here are acceptable values.

Typically, the swirl velocities (model's results) at the depth level of $600 \mathrm{~m}$ are higher than at $1000 \mathrm{~m}$. Anticyclones tend to rotate faster than cyclones and peak azimuthal velocities are about $30 \mathrm{~cm} \mathrm{~s}^{-1}$. Both results are in agreement with values reported in past work (Richardson et al., 2000; Carton et al., 2002; Serra and Ambar, 2002). However, records in Meddies with dynamical radius smaller than $10 \mathrm{~km}$ have revealed velocities as high as 50 $\mathrm{cm} \mathrm{s}^{-1}$ (Carton et al., 2010).

Past observations give reasons to believe that the swirl velocity tends to decrease slightly as the distance to the point of origin increases: a behaviour 
that is confirmed inhere at least at $z=600 \mathrm{~m}$ (Figure 5). Moreover, measurements of distinct rotation rates, at different depths within recently formed Meddies, suggest that the characteristic solid-body rotation of Meddies is acquired as they evolve (Ambar et al., 2008). This is also supported by our results where the largest differences in swirl velocity (at $600 \mathrm{~m}$ or $1000 \mathrm{~m}$ depth) occur within the first $500 \mathrm{~km}$ since the point of origin.

Here, there is also an indication of distinct swirl velocities between Meddies formed in Cape St. Vincent or Portimão Canyon and Estremadura Promontory which could be related to different generation mechanisms.

From measurements of floats inside Meddies in the open ocean, Richardson and Tychensky (1998) reported mean translation speeds of $2.5 \pm 0.5 \mathrm{~cm}$ $\mathrm{s}^{-1}$, which is in good agreement with the mean value of $\sim 3 \mathrm{~cm} \mathrm{~s}^{-1}$ obtained here. The minimum value of $1.1 \mathrm{~cm} \mathrm{~s}^{-1}$ is also corroborated by past observations of Richardson et al. (1989). In spite of the limitation on speed imposed by our tracking method (see Appendix A and Section 4.1.5), the maximum translation speed detected here, $6.2 \mathrm{~cm} \mathrm{~s}^{-1}$, agrees well with the largest time-mean speeds of $6.4 \mathrm{~cm} \mathrm{~s}^{-1}$ recorded in observations (Richardson et al., 2000).

Regarding temperature measurements, instantaneous observations in Meddies range from $11.4^{\circ} \mathrm{C}$ to $13^{\circ} \mathrm{C}$ (Serra and Ambar, 2002), while in cyclones the values vary from $11^{\circ} \mathrm{C}$ to $12^{\circ} \mathrm{C}$ (Carton et al., 2002; Serra and Ambar, 2002; Ambar et al., 2008). Our results indicate time-mean values around $12^{\circ} \mathrm{C}$ in anticyclones and $11^{\circ} \mathrm{C}$ in cyclones. The latter are on average colder than their counterparts as suggested by the earliest measurements in cyclones by Richardson et al. (2000).

Also, our results show that anticyclones are slightly more saline than cyclones. Note how the salinity is lower inside the cyclonic core in the two examples of dipoles off Portimão Canyon and Estremadura Promontory (Figures 8 and 9). This is also supported by observations by Carton et al. (2002); Ambar et al. (2008) who reported maximum values of 36.5 - 36.6 psu for anticyclones and $36.2-36.4$ psu for cyclones, in dipoles surveyed in the Gulf of Cadiz.

The temperature and salinity anomalies presented here were computed differently than what is usual in observational data. The extreme and mean values produced here are smaller than typical values reported in observations. Nevertheless, the anomalies obtained are comparatively stronger in anticyclones than in cyclones, as learned from in situ surveys as well.

Despite not being very common, some measurements within anticyclones 
in the Gulf of Cadiz (Carton et al., 2010) show that these will occasionally have a strong salinity anomaly below $1300 \mathrm{~m}$. Such Meddies are unlikely to be detected by the Meddy criteria used here and this may hinder the detection of Meddies in the Gulf of Cadiz.

The eddy tracking results bear evidence that the dynamical signature of cyclones is shallower than that of anticyclones. This brings further support to the hypothesis that cyclones will often form above and to the side of an anticyclone when the latter detaches from a cape or canyon, forming a baroclinic dipole (Serra et al., 2002; Aiki and Yamagata, 2004). Likewise, the weaker thermohaline anomalies of cyclones versus anticyclones favour the possibility that cyclones will gather water from the Upper Core, unlike anticyclones whose MW content is largely provided by the Lower Core. Detailed hydrographic observations of dipoles are in agreement with this interpretation (Carton et al., 2002).

Since more cyclones are found in the Gulf of Cadiz than elsewhere this suggests that either the formation mechanisms of Meddies over there are more prone to forming also cyclones (i.e. dipoles are formed), or (possibly "and") that cyclones survive longer there. The canyon formation mechanism implies first the formation of a cyclone followed by the formation of an anticyclone downstream; they are asymmetrical in a shallow-water model if the flow initially has potential vorticity $\left(\omega_{c}+f\right) /(h+\delta h)=\left(\omega_{0}+f\right) / h=\left(\omega_{a}+f\right) /(h-\delta h)$ or possibly the $\omega_{c}$ and $\omega_{a}$ (relative vorticity of the cyclone and anticyclone, respectively) can be due to different mechanisms such as topography for the first one and curvature for the second one; where $f$ is the Coriolis parameter, $\omega_{0}$ is the initial relative vorticity of the MW undercurrent, $h$ is its initial thickness and $\delta h$ is its thickness variation due to topography.

In sigma-coordinate models, the realism of topography is a compromise between the desired steepness of the terrain and a spurious pressure gradient force generated over very steep slopes. To reduce the latter effect, a substantial amount of smoothing is required unless the resolution is very high. In our case, even with a $3 \mathrm{~km}$ resolution, the topography had to be smoothed. Although the relevant details of the topography such as promontories, canyons and seamounts are preserved here, future simulations should consider higher resolutions (smaller than $2 \mathrm{~km}$ ). An improved topography (steepness) and higher vertical resolutions may significantly increase the realism of the outflow and of the Meddies' generation ultimately. 


\section{Conclusions}

In the present work, the Mediterranean Outflow was simulated at high resolution, over a period of 20 years. The simulation included atmospheric forcing and the boundary conditions at the Strait of Gibraltar were taken from a previous numerical study which focused on Mediterranean-Atlantic exchanges. The output velocity fields were searched for eddies at two depth levels: 600 and $1000 \mathrm{~m}$. The eddies were tracked throughout their life-times and those containing MW (Meddies) were identified using a criteria that takes into account the salinity anomaly vertically-averaged between 600 and $1300 \mathrm{~m}$. The formation of Meddies was recurrent and the domain was large enough to allow the structures to freely evolve, following their natural fate. The large number of records ensures the statistical significance of the results gathered here. Nevertheless, the population of Meddies varied depending on the thresholds used for the Meddies' life-time and salinity anomaly.

For Meddies living a minimum of 15 days and having a minimum salinity anomaly of $0.12 \mathrm{psu}$, the formation rates along the southwestern Iberian slope are of 16-18 Meddies per year. Considering the whole domain of study, 28$31 \%$ of the Meddies within this dataset are cyclones. Among the datasets studied here, this one exhibits the slope's formation rate and fraction of cyclones that are closer to previous estimates based on observational records.

Some robust Meddies form far from the slope, in the Tagus Abyssal Plain and Horseshoe seamounts. These events are likely to be due to merging or re-birth of previously existing Meddies as illustrated above. In the future, such events will be studied in more detail.

There is an abundance of cyclones (anticyclones) upstream (downstream) of Cape St. Vincent which is most certainly an indicator of different underlying dynamics. However, it is not clear whether this asymmetry is due to the generation process itself or the evolution of each type of structure. The longest-lived Meddies propagate northwestward: while anticyclones depart from the western slope, cyclones depart from the southern Iberian slope. Most of the anticyclones will also veer southwestwards but the cyclones will either move northwestwards or recirculate in the Gulf of Cadiz. Three cyclones (much less than anticyclones) that live longer than 90 days and with a salinity anomaly above 0.3 psu can only be seen off Portimão Canyon at $z=1000 \mathrm{~m}$, probably because the dynamical core lies deeper in these Meddies. Larger survival rates of cyclones near Portimão Canyon may be due to trapping by topography, to the recirculation gyre, or to re-intensification 


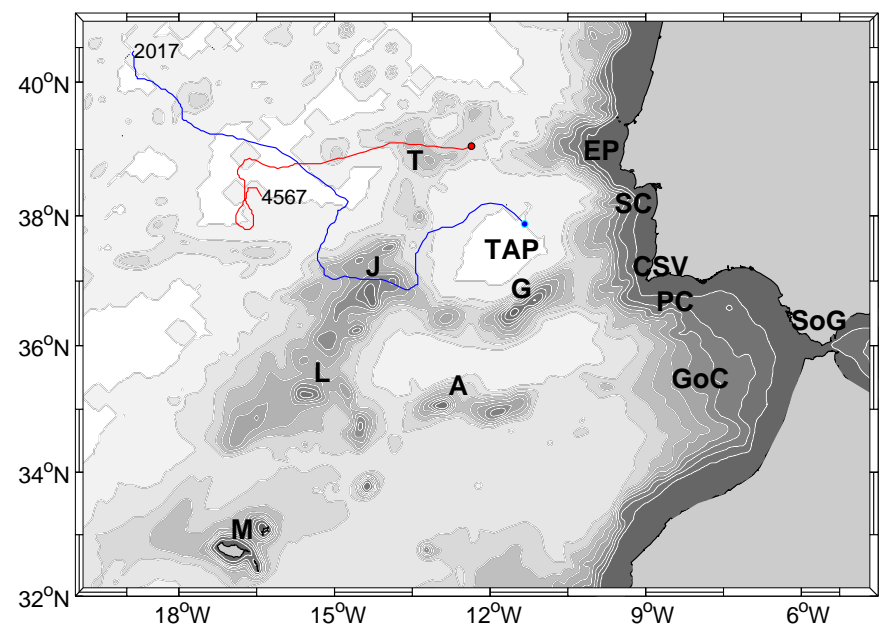

Figure 1: Domain of study with bathymetry shown in gray scale at regular intervals of $500 \mathrm{~m}$. Strait of Gibraltar (SoG), Gulf of Cadiz (GoC), Madeira Island (M), Tore Seamount (T) and Tagus Abyssal Plain (TAP). Southwestern Iberian slope: Portimão Canyon (PC), Cape St. Vincent (CSV), Setubal Canyon (SC), Estremadura Promontory (EP). Horseshoe Seamounts: Josephine (J), Lion (L), Ampère (A) and Gorringe bank (G). The red (anticyclone) and blue (cyclone) lines correspond to examples of Meddies and the circles mark the Meddies' birthplace (see Figure B.11).

processes and this remains an open question.

In future work, the results from realistic numerical simulations will be used to study in detail the processes of formation, interaction and disruption of Meddies in the main locations identified inhere.

\section{Acknowledgments}

The authors would like to thank F. Nencioli for providing the source code of his automatic eddy detection algorithm. This study had the support of Fundação para a Ciência e Tecnologia (FCT) through the projects MedEx (MARIN-ERA/MAR/0002/2008) and Sflux (PTDC/MAR/100677/2008). A. C. Barbosa Aguiar was funded through the grant SFRH/BPD/64099/2009 by the FCT. X. Carton acknowledges the support of SHOM for the SEMANE programme. 

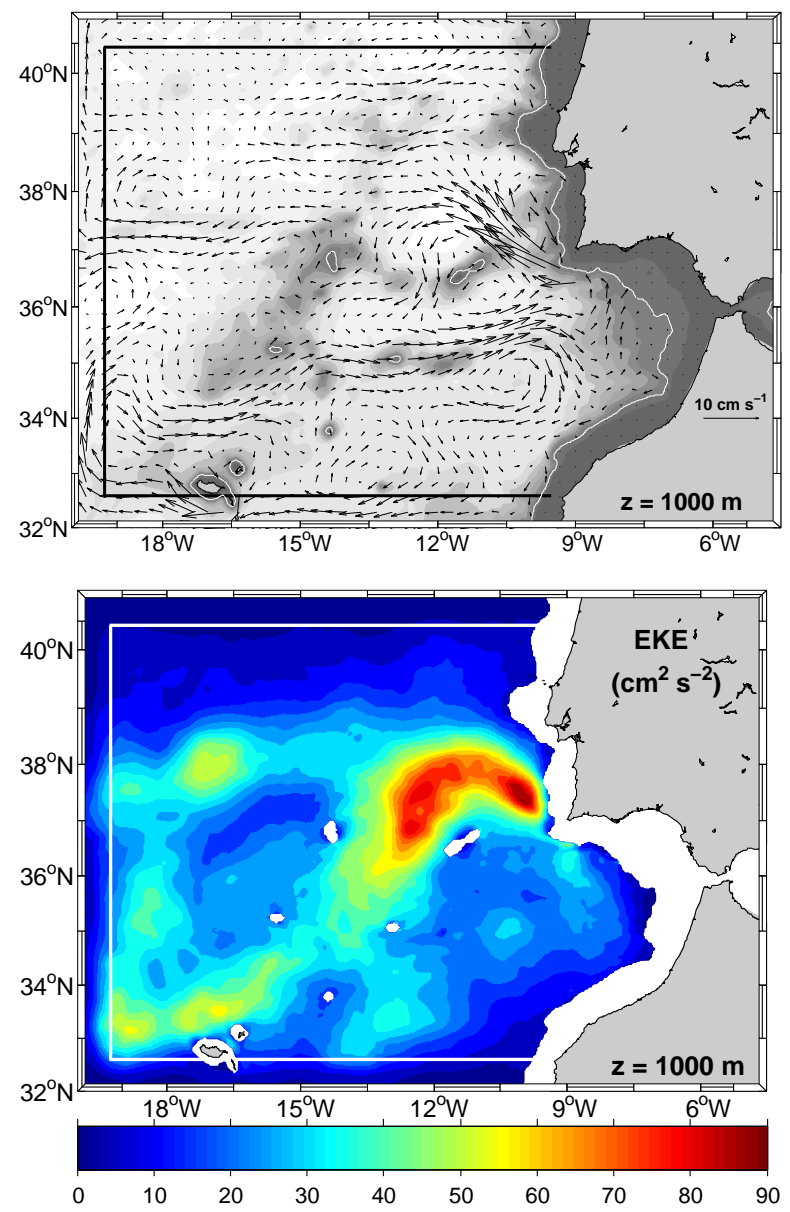

Figure 2: Top: Mean velocity field (20-years) with vectors represented at each 10 gridpoints and the $1000 \mathrm{~m}$ isobath in white. Bottom: Eddy Kinetic Energy (20-years). The straight lines (black/white) give the approximate limits of the sponge band (see Section 2.2). 

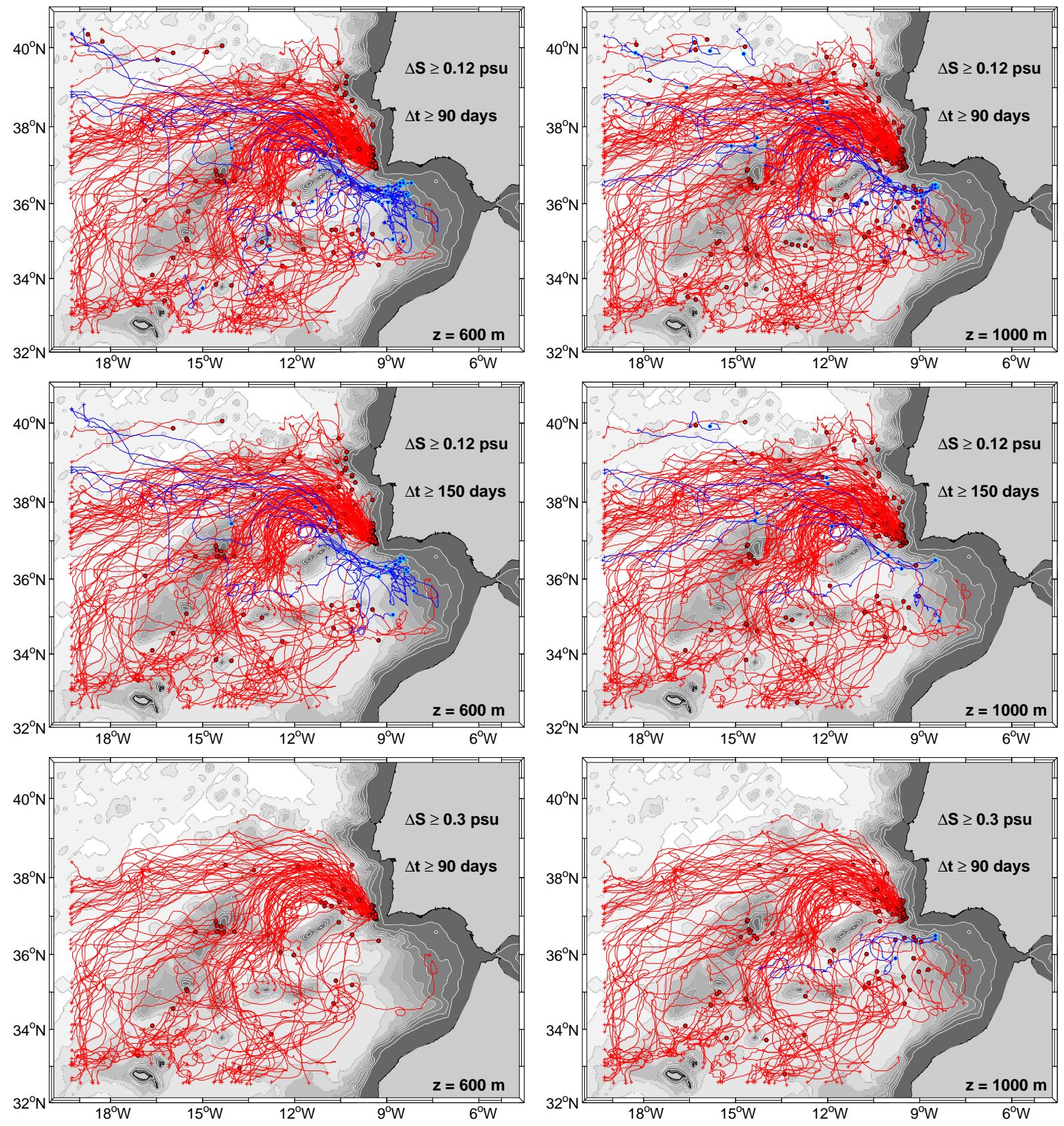

Figure 3: Trajectories of Meddies born during 20 yrs of simulation in the whole domain $(r=18 \mathrm{~km})$ : comparison of trajectories for different thresholds of eddy life-time $\Delta t$ and minimum salinity anomaly $\Delta S$ (mean over at least half the life-time), at the respective $z$-level. Red (blue) lines correspond to anticyclones (cyclones) while circles in different colour mark their "birth". The bathymetry is shown in gray scale at regular intervals of $500 \mathrm{~m}$. 

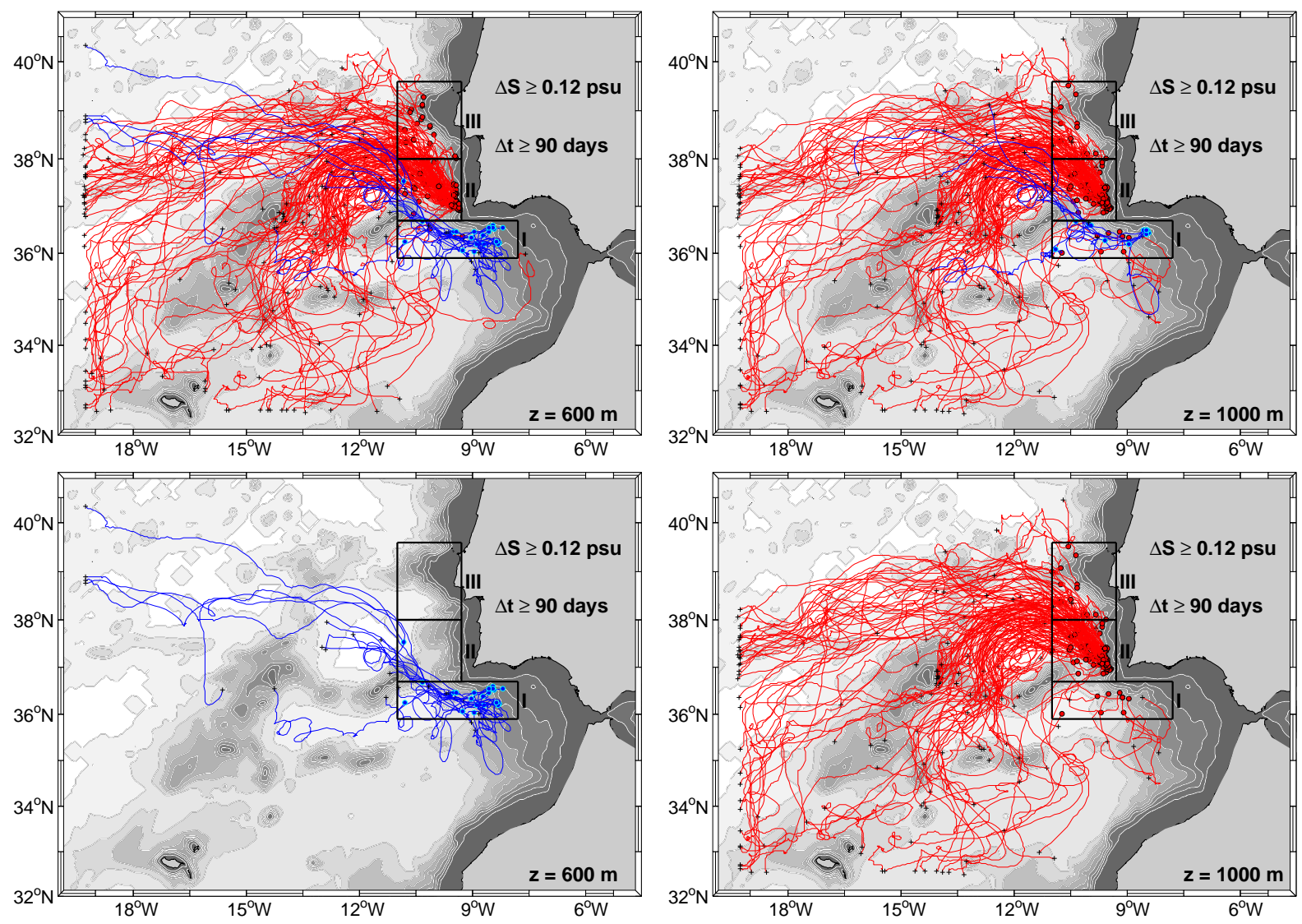

Figure 4: Trajectories of Meddies born within boxes I, II and III during 20 yrs of simulation. This is a subset of the whole domain population $(\Delta S \geq 0.12 \mathrm{psu}$ and $\Delta t \geq 90$ days) shown in Figure 3 (top). Bottom-left: only cyclones tracked at $z=600 \mathrm{~m}$. Bottom-right: only anticyclones tracked at $z=1000 \mathrm{~m}$. Red (blue) lines correspond to anticyclones (cyclones), while circles in different colour mark their "birth" and black crosses mark their "death". The boxes correspond to the three slope regions of Meddies' formation (see Section 4.2.1). The bathymetry is shown in gray scale at regular intervals of $500 \mathrm{~m}$. 

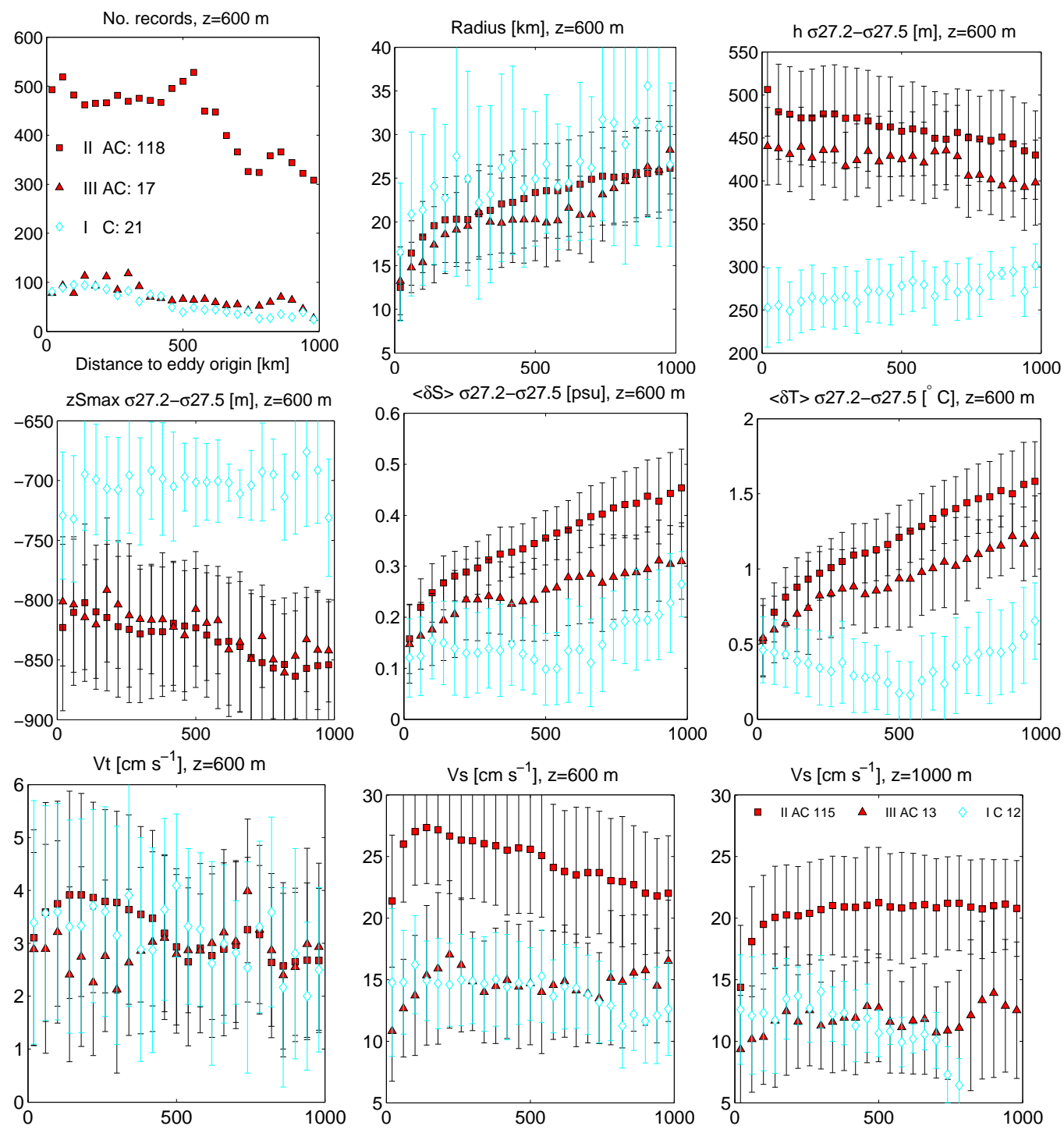

Figure 5: Properties of Meddies born in boxes I, II and III ( $\Delta S \geq 0.12$ psu and $\Delta t \geq 90$ days, Figure 4) as a function of curvilinear distance to origin, for eddy tracking at $z=600$ $\mathrm{m}$. In the first chart is shown the number of records available in each case and the numbers in the legend correspond to the total of Meddies born in each box. In the remaining charts are represented the mean values (markers) and the standard deviation (errorbars) computed with all the records collected at each $40 \mathrm{~km}$ of distance (see Section 4.2.3 for details). Swirl velocity at $z=1000 \mathrm{~m}$ is shown in the last graph, with the total of Meddies per box in the legend. 


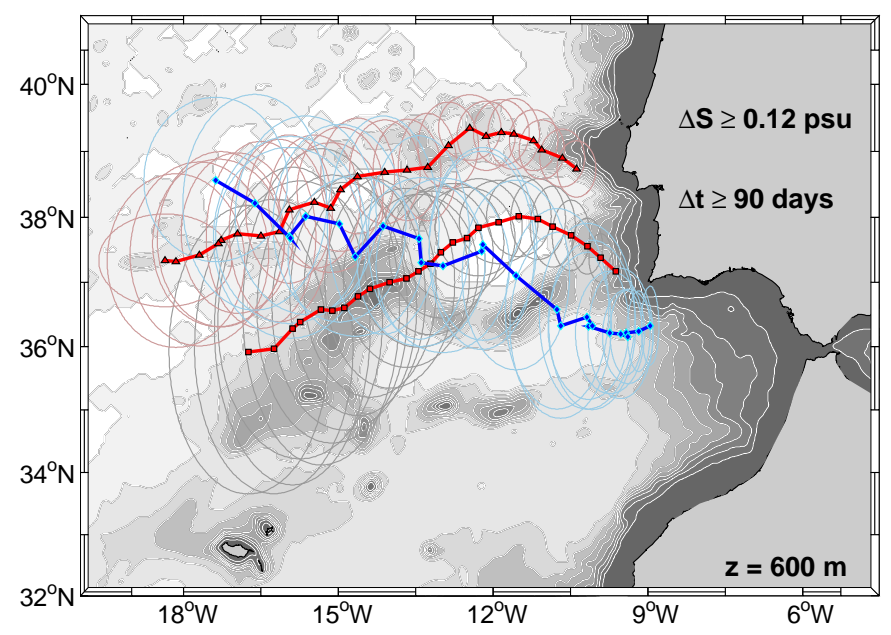

Figure 6: Mean trajectories of Meddies born in boxes I, II, and III, corresponding to the dataset analysed in Figure 5 and shown in Figure 4. The standard deviation on longitude and latitude is represented by the size of the horizontal and vertical axis of each ellipse. The ellipses corresponding to data from box I, II and III are coloured in light blue, gray and pink respectively.
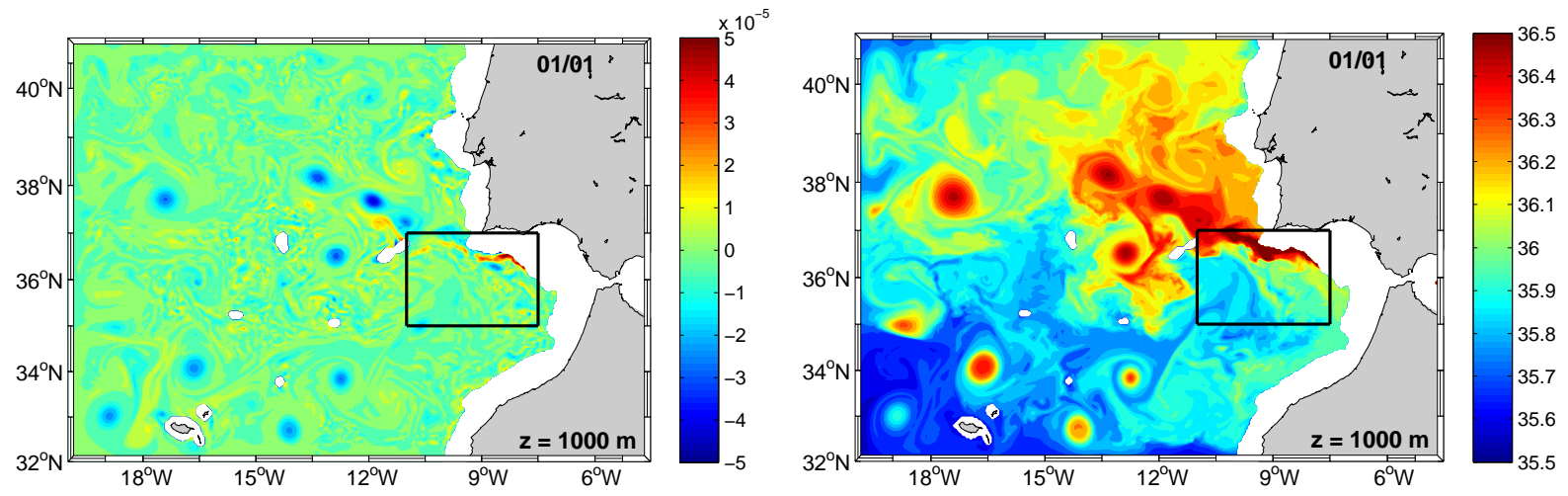

Figure 7: Snapshots of vorticity $\left(\mathrm{s}^{-1}\right)$ and salinity (psu) fields at $z=1000 \mathrm{~m}$ on the left and right, respectively. See Figure 8 for a time-sequence of the area within the black box. 

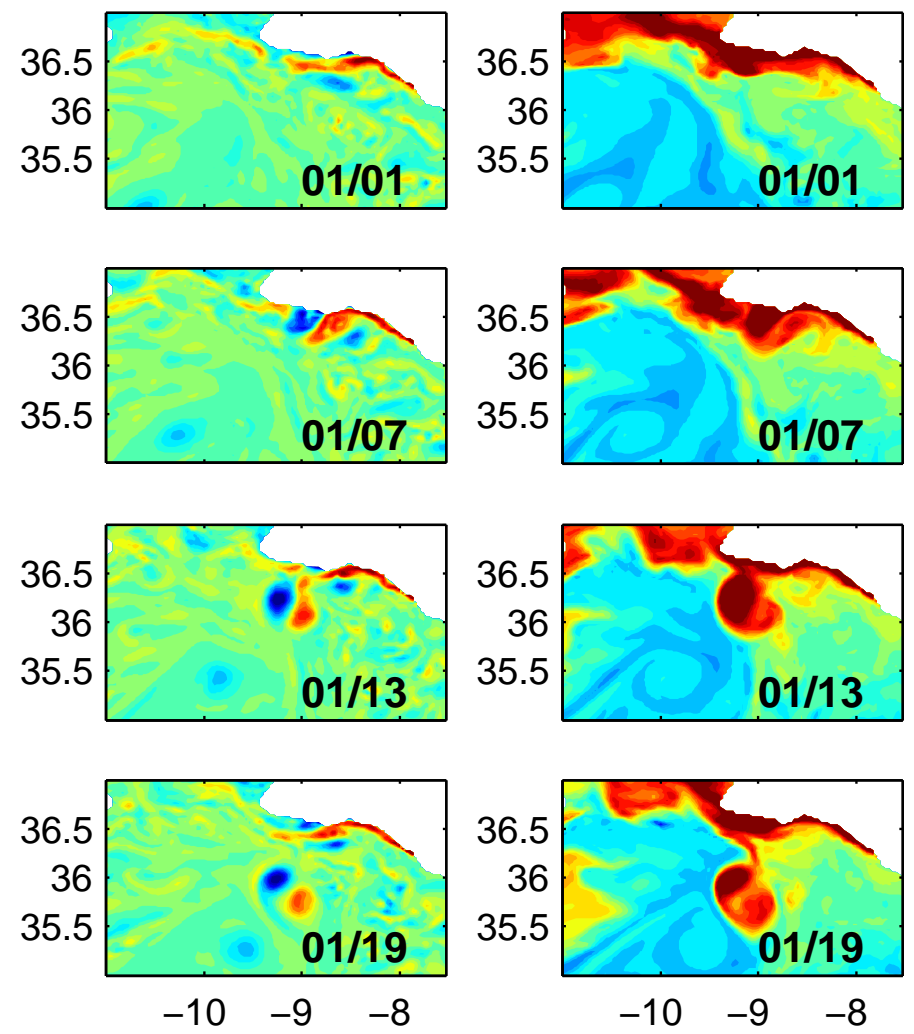

Figure 8: Time sequence of vorticity and salinity fields during the generation of a dipole off Portimão Canyon (same colourscale and depth as in Figure 7). Time is given in each frame as $m m / d d: m m=$ month, $d d=$ day. 

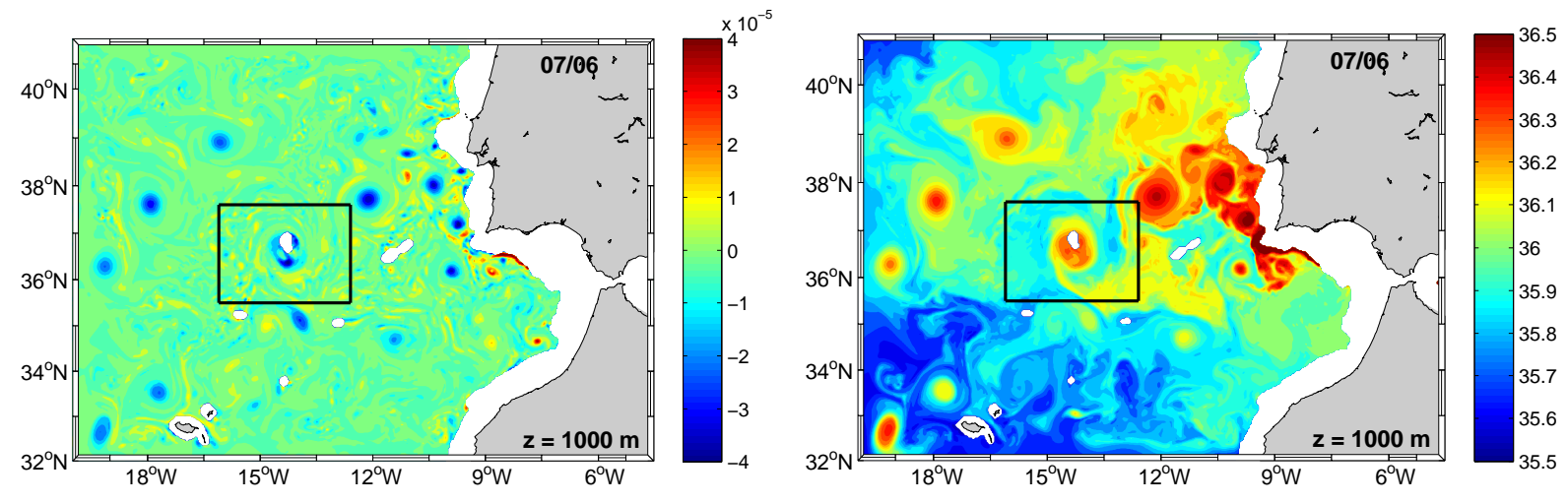

Figure 9: Snapshots of vorticity $\left(\mathrm{s}^{-1}\right)$ and salinity (psu) fields at $z=1000 \mathrm{~m}$ on the left and right, respectively. Note the formation of a small dipole at about $\left(11^{\circ} \mathrm{W}, 38.5^{\circ} \mathrm{N}\right)$. See Figure 10 for a time-sequence of the area within the black box.
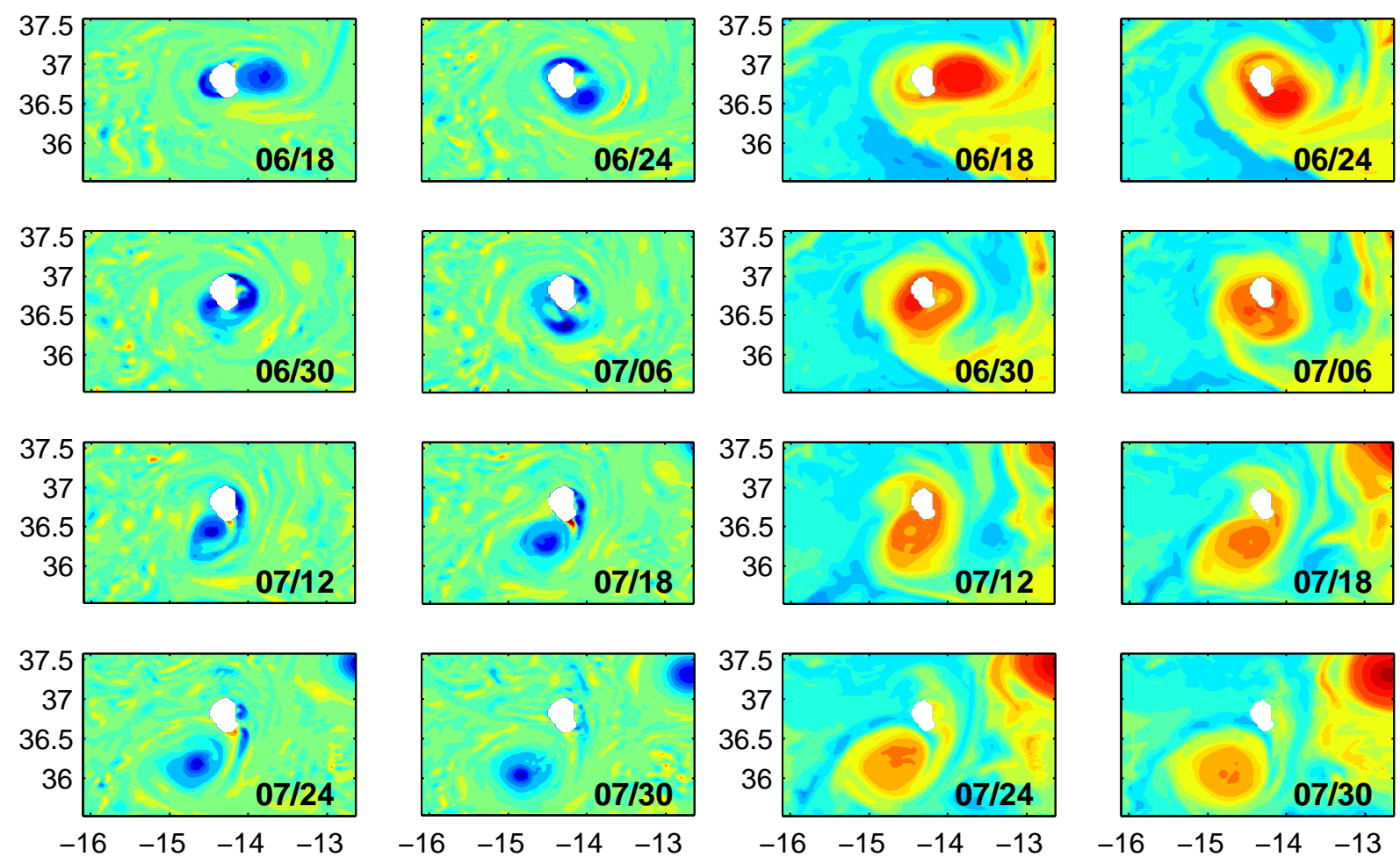

Figure 10: Time sequence of vorticity and salinity fields depicting the "death" (06/24) and "birth" (07/06) of a Meddy at Josephine seamount (same colourscale and depth as in Figure 9). Time is given in each frame as $m m / d d: m m=$ month, $d d=$ day. 


\begin{tabular}{|c|c|c|c|c|}
\hline \multicolumn{2}{|c|}{$\Delta S \geq$} & 0.12 & 0.2 & 0.3 \\
\hline$z=600 \mathrm{~m}$ & Total units $\mathrm{yr}^{-1}$ & 11 & 8.1 & 5.2 \\
\hline$r=18 \mathrm{~km}$ & $\% \mathrm{C}$ & 14 & 4 & 0 \\
\hline$z=1000 \mathrm{~m}$ & Total units $\mathrm{yr}^{-1}$ & 12.2 & 8.9 & 6 \\
\hline$r=18 \mathrm{~km}$ & $\% \mathrm{C}$ & 12 & 5 & 3 \\
\hline$z=600 \mathrm{~m}$ & Total units $\mathrm{yr}^{-1}$ & 10.5 & 7.6 & 5 \\
\hline$r=36 \mathrm{~km}$ & $\% \mathrm{C}$ & 14 & 2 & 0 \\
\hline$z=1000 \mathrm{~m}$ & Total units $\mathrm{yr}^{-1}$ & 11.4 & 8.4 & 5.5 \\
\hline$r=36 \mathrm{~km}$ & $\% \mathrm{C}$ & 13 & 5 & 3 \\
\hline
\end{tabular}

Table 1: Time-mean Rates of Formation in the Whole Domain. For datasets of Meddies with different $\Delta S$ [psu] thresholds and $\Delta t \geq 90$ days (see Figure 3 top and bottom). Total units $\mathrm{yr}^{-1}$ : rates of formation of anticyclones and cyclones altogether; \% $\mathrm{C}$, percentage of cyclones.

\begin{tabular}{|c|c|c|c|c|}
\hline \multicolumn{2}{|c|}{$\Delta S \geq$} & 0.12 & 0.2 & 0.3 \\
\hline$z=600 \mathrm{~m}$ & Total units $\mathrm{yr}^{-1}$ & 4.3 & 3.3 & 2.8 \\
\hline$r=18 \mathrm{~km}$ & \% Meddies & 39 & 41 & 54 \\
\hline$z=1000 \mathrm{~m}$ & Total units $\mathrm{yr}^{-1}$ & 4.5 & 3.6 & 3 \\
\hline$r=18 \mathrm{~km}$ & \% Meddies & 37 & 41 & 50 \\
\hline$z=600 \mathrm{~m}$ & Total units $\mathrm{yr}^{-1}$ & 4.4 & 3.4 & 2.9 \\
\hline$r=36 \mathrm{~km}$ & \% Meddies & 42 & 45 & 57 \\
\hline$z=1000 \mathrm{~m}$ & Total units $\mathrm{yr}^{-1}$ & 4.4 & 3.6 & 2.9 \\
\hline$r=36 \mathrm{~km}$ & \% Meddies & 39 & 43 & 52 \\
\hline
\end{tabular}

Table 2: Rates of Exit to the North Atlantic. For datasets of Meddies with different $\Delta S$ [psu] thresholds and $\Delta t \geq 90$ days (see Figure 3 top and bottom). Total units $\mathrm{yr}^{-1}$ : rates of exit of anticyclones and cyclones altogether; \% Meddies, percentage of Meddies formed that succeed in exiting the domain. 


\begin{tabular}{|c|c|c|c|c|c|c|c|c|c|}
\hline & $\begin{array}{c}\Delta t \\
\text { (days) }\end{array}$ & $\begin{array}{c}\Delta d \\
(\mathrm{~km})\end{array}$ & $\begin{array}{c}R \\
(\mathrm{~km})\end{array}$ & $\begin{array}{c}V_{s} \\
\left(\mathrm{~cm} \mathrm{~s}^{-1}\right)\end{array}$ & $\begin{array}{c}V_{t} \\
\left(\mathrm{~cm} \mathrm{~s}^{-1}\right)\end{array}$ & $\begin{array}{c}\mathrm{S} \\
(\mathrm{psu})\end{array}$ & $\begin{array}{c}\delta S \\
(\mathrm{psu})\end{array}$ & $\begin{array}{c}\mathrm{T} \\
\left({ }^{\circ} \mathrm{C}\right)\end{array}$ & $\begin{array}{c}\delta T \\
\left({ }^{\circ} \mathrm{C}\right)\end{array}$ \\
\hline \multicolumn{10}{|c|}{$190 A C, z=600 \mathrm{~m}$} \\
\hline $\min$ & 90 & 105 & 10 & 4 & 1.1 & 35.9 & 0.10 & 10.7 & 0.51 \\
\hline $\max$ & 1011 & 1987 & 64 & 32 & 6.2 & 36.5 & 0.54 & 12.8 & 2.22 \\
\hline mean & 321 & 805 & 23 & 21 & 3.1 & 36.3 & 0.31 & 12.2 & 1.34 \\
\hline \multicolumn{10}{|c|}{$31 C, z=600 \mathrm{~m}$} \\
\hline $\min$ & 90 & 153 & 13 & 8 & 1.7 & 35.8 & 0.1 & 10.2 & 0.09 \\
\hline $\max$ & 492 & 1253 & 50 & 23 & 6 & 36.3 & 0.29 & 11.6 & 0.72 \\
\hline mean & 207 & 549 & 27 & 13 & 3.2 & 36.1 & 0.17 & 11.1 & 0.35 \\
\hline \multicolumn{10}{|c|}{$216 A C, z=1000 \mathrm{~m}$} \\
\hline $\min$ & 90 & 121 & 11 & 3 & 1.5 & 35.9 & 0.11 & 10.7 & 0.41 \\
\hline $\max$ & 1011 & 1969 & 48 & 28 & 6.1 & 36.5 & 0.57 & 12.8 & 2.44 \\
\hline mean & 291 & 728 & 24 & 16 & 3.1 & 36.3 & 0.31 & 12.1 & 1.31 \\
\hline \multicolumn{10}{|c|}{$28 C, z=1000 \mathrm{~m}$} \\
\hline $\min$ & 93 & 118 & 15 & 4 & 1.5 & 36 & 0.09 & 10.5 & 0.11 \\
\hline $\max$ & 378 & 795 & 47 & 16 & 5.2 & 36.3 & 0.32 & 11.8 & 0.94 \\
\hline mean & 165 & 417 & 24 & 10 & 3 & 36.2 & 0.17 & 11.1 & 0.38 \\
\hline
\end{tabular}

Table 3: Properties of Meddies in the Whole Domain, $\Delta t \geq 90$ days and $\Delta S \geq 0.12 \mathrm{psu}$ (Figure 3 top). AC, anticyclones; C, cyclones; $\Delta t$, eddy life-time; $\Delta d$, distance travelled; $R$, radius (given by the median radius of each eddy); $V_{s}$ and $V_{t}$ are respectively the swirl and translation velocity; $S, \delta S, T$ and $\delta T$ are respectively the salinity, salinity anomaly, temperature and temperature anomaly depth-averaged between $z=600 \mathrm{~m}$ and $z=1300$ $\mathrm{m}$, along the vertical axis of the eddy "centre" detected at $z=600 \mathrm{~m}$ or $z=1000 \mathrm{~m}$. $V_{s}$, $V_{t}, S, \delta S, T$ and $\delta T$ correspond to time-averaged values along an eddy's trajectory. 


\begin{tabular}{|c|c|c|c|c|c|c|c|c|c|}
\hline & & \multicolumn{4}{|c|}{$\Delta t \geq 15$ days } & \multicolumn{4}{|c|}{$\Delta t \geq 90$ days } \\
\hline & & I & II & III & WD & $\mathrm{I}$ & II & III & WD \\
\hline$z=600 \mathrm{~m}$ & Total units $\mathrm{yr}^{-1}$ & 5.5 & 9.2 & 1.3 & 29 & 1.2 & 6 & 0.9 & 11 \\
\hline$r=18 \mathrm{~km}$ & $\% \mathrm{C}$ & 84 & 4 & 4 & 31 & 91 & 0.8 & 0 & 14 \\
\hline$z=1000 \mathrm{~m}$ & Total units $\mathrm{yr}^{-1}$ & 7.2 & 9.3 & 1.4 & 40 & 1 & 5.8 & 0.7 & 12 \\
\hline$r=18 \mathrm{~km}$ & $\% \mathrm{C}$ & 61 & 3 & 4 & 28 & 57 & 0 & 0 & 12 \\
\hline$z=600 \mathrm{~m}$ & Total units $\mathrm{yr}^{-1}$ & 4.8 & 9 & 1.4 & 26 & 1 & 5.9 & 0.9 & 10.5 \\
\hline$r=36 \mathrm{~km}$ & $\% \mathrm{C}$ & 83 & 4 & 4 & 30 & 90 & 0.9 & 0 & 14 \\
\hline$z=1000 \mathrm{~m}$ & Total units $\mathrm{yr}^{-1}$ & 6.6 & 9 & 1.2 & 36 & 1.3 & 5.8 & 0.5 & 11.4 \\
\hline$r=36 \mathrm{~km}$ & $\% \mathrm{C}$ & 63 & 2 & 0 & 28 & 48 & 0 & 0 & 13 \\
\hline
\end{tabular}

Table 4: Rates of Formation of Meddies per Region, $\Delta S \geq 0.12$ psu. Total units $\mathrm{yr}^{-1}$ : rates of formation of anticyclones and cyclones altogether; $\% \mathrm{C}$, percentage of cyclones born within each region; WD, Whole Domain. 


\section{Appendix A. Eddy Tracking}

In order to identify vortices in the horizontal velocity fields, the algorithm developed by Nencioli et al. (2010) starts by locating their centres. To do so, the algorithm searches for points where the following constraints are verified.

1. In the zonal direction, it searches for a pair of grid-points such that the meridional velocity i) reverses its sign and ii) has increasing magnitude within $a$ grid-points to each side of the pair. For the points thus selected, the same procedure is applied along the meridional direction for the zonal velocity.

2. The algorithm then searches for a local minimum of velocity in a square of side $2 b \times 2 b$ centred on one of the points identified in step 1 . That local minimum is considered a candidate for the centre assuming it passes a similar check.

3. To discard non-eddy structures that pass the previous constraints, the velocity vectors are checked to exhibit a constant sense of rotation around the candidate eddy's centre.

Once identified, the coordinates of the eddy's centre and boundary are recorded and the eddy can be tracked along consecutive velocity fields. For further details see Nencioli et al. (2010).

After comparing the eddies' centres obtained with different values of search parameters (not shown), we decided to use $a=4$ and $b=3$ which provided the most successful detection. This choice sets the radius of the smallest detectable vortices to $9-12 \mathrm{~km}$, given the model's spatial-resolution of $3 \mathrm{~km}$.

An eddy's boundary was defined as the outermost closed streamline, within a specified number of grid-points (nrad $=8)$ from the eddy's centre (in a first instance), where the velocity magnitude was still increasing in the radial direction. This area was enlarged whenever necessary to accommodate for larger eddies. The radius of the eddy was estimated as the mean distance from every boundary-point to the centre of the eddy. There is no optimal criterion to determine the dimensions of an eddy automatically detected and, while the method adopted here may lead to a slight underestimation of the radius (see Nencioli et al., 2010, Figure 6), it is guaranteed to return the dimensions of closed structures.

The trajectories are retrieved by following each eddy across consecutive velocity fields: two eddies identified separately at $t$ and $t+1$ are considered 
to be the same structure if they have the same vorticity sign and if the distance between the two is smaller or equal to $r=\{18,36\} \mathrm{km}$ (Nencioli et al. (2010), Section 3c). This algorithm is able to track eddies across non-consecutive velocity fields, which is an advantage since these eddies will often suffer strong distortions and loose their dynamical signature during interactions with neighbouring eddies or topography. However, if the eddy does not recover a coherent signal after two consecutive maps, its tracking ends.

In addition, a minimum eddy life-time of $\Delta t=N \cdot \delta t_{\text {out }} \geq 15$ days was imposed by selecting only the trajectories with a minimum of 5 points $(N \geq 5)$.

After running the eddy tracking algorithm over the 20 years of numerical data, a total of 6030 and 6835 (5767 and 6691) eddies were identified at $z=600 \mathrm{~m}$ and $z=1000 \mathrm{~m}$, respectively, for $r=18 \mathrm{~km}(r=36 \mathrm{~km})$.

The translation speed of the eddies detected was limited to 7 or $14 \mathrm{~cm}$ $\mathrm{s}^{-1}$ when using $r=18 \mathrm{~km}$ or $r=36 \mathrm{~km}$, respectively. While it is desirable to allow for maximum speeds closer to the observed maxima of $17 \mathrm{~cm} \mathrm{~s}^{-1}$ (Richardson et al., 2000), this incurred a higher risk of merging the trajectories of two independent eddies of the same vorticity sign, if: 1 . one vanished and 2. the other formed within the same area and at about the same time. Some results are presented here for both values of parameter $r$, but most of the results discussed focus on the dataset of eddies obtained with $r=18 \mathrm{~km}$.

\section{Appendix B. Selection of Meddies}

In order to check whether an eddy should be classified as a Meddy or not, we computed the salinity anomaly profile corresponding to every point of its trajectory: $\Delta S^{*}(t, z), t=\{1, \ldots, N\}$, as illustrated in Figure B.11 (top). This anomaly was computed with respect to the local monthly values of salinity time-averaged over the 20 years; in other words, this anomaly corresponded to the salinity profile at the eddy centre minus the local 20year mean salinity.

Then, a characteristic salinity anomaly at MW levels was computed for each eddy: by depth-averaging $\Delta S^{*}(t, z)$ over $z$-levels within the upper $600 \leq$ $z<1000 \mathrm{~m}(\mathrm{UMW})$ and deeper $1000 \leq z<1300 \mathrm{~m}$ (DMW) layers.

In the end, an eddy would be classified as a Meddy only if its depthaveraged salinity anomaly was above a threshold value $\Delta S$ during a fraction of its life-time $\gamma=\left(n_{U M W}+n_{D M W}\right) /(2 N)$; here $N$ is the total of points in 

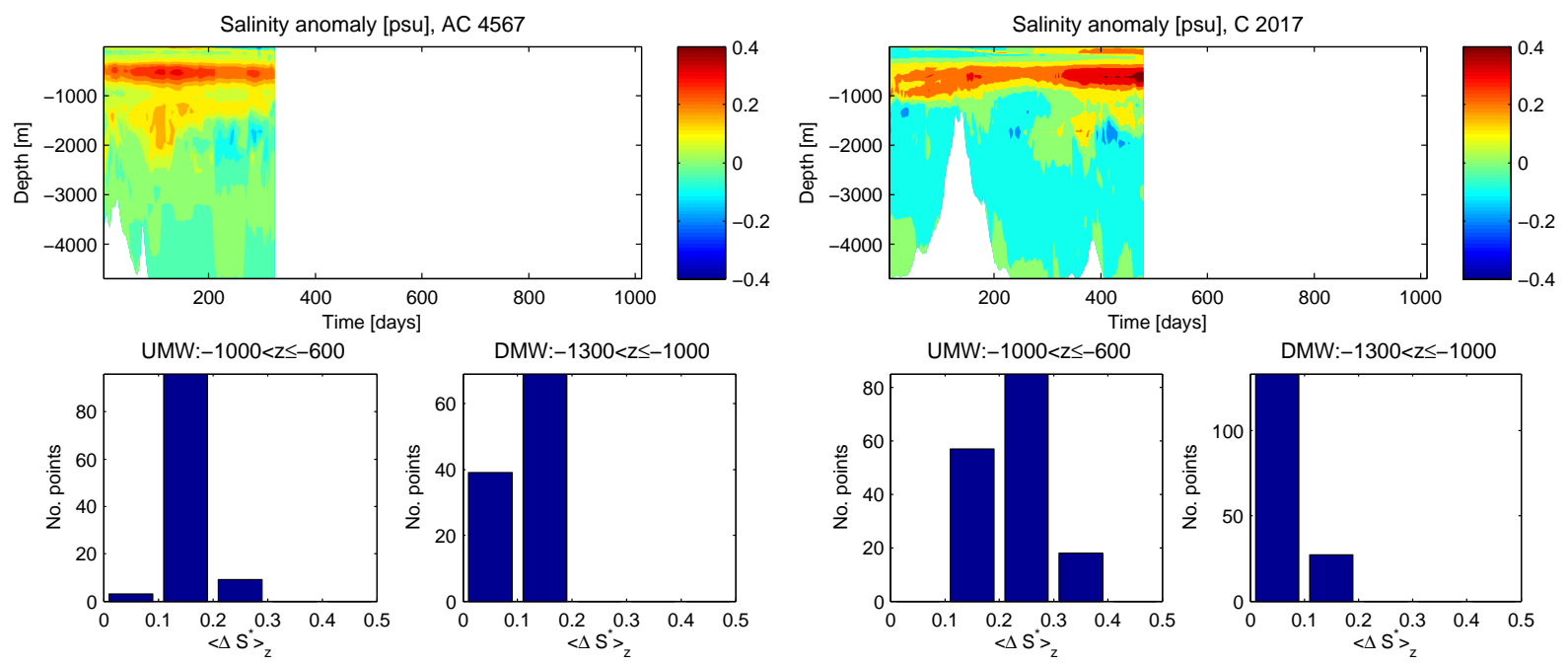

Figure B.11: Top: depth-profiles of the salinity anomaly recorded for an AC (left) and a $\mathrm{C}$ (right), both tracked at $z=600 \mathrm{~m}$ along the trajectories shown in Figure 1. Bottom: histograms of the depth-averaged salinity anomaly computed over the Upper or Deeper Mediterranean Water levels (UMW, DMW), at each point (instant of time) of the eddy's trajectory; if at least half of the points exhibit $\langle\Delta S\rangle_{z}$ above a specified threshold, then the eddy is classified as a Meddy (see Appendix B for more details).

the trajectory, $n_{U M W}$ is the number of points with $\left\langle\Delta S^{*}\right\rangle_{U M W}(t) \geq \Delta S$ and likewise for $n_{D M W}$ (see histograms in Figure B.11 bottom).

When first plotting all trajectories of Meddies, some boundary effects were evidenced by Meddies recirculating along the boundaries due to the effect of the sponge layers on the eddy vorticity. Therefore, all the records of Meddies within approximately $65 \mathrm{~km}$ to the boundaries were discarded before performing the statistics below. That distance corresponds to the sponge's width plus $15 \mathrm{~km}$, permitting mean-sized Meddies (radius below $30 \mathrm{~km}$, see Table 3) to penetrate at most $30 \%$ of the sponge layer.

\section{References}

Aiki, H., Yamagata, T., 2004. A numerical study on the successive formation of Meddy-like lenses. J. Geophys. Res. 109, C06020. doi:10.1029/2003JC001952.

Ambar, I., 1983. A shallow core of Mediterranean Water off western Portugal. Deep-Sea Res. 30, 677-680. 
Ambar, I., Serra, N., Neves, F., Ferreira, T., 2008. Observations of the Mediterranean Undercurrent and eddies in the Gulf of Cadiz during 2001. J. Marine Sys. 71, 195-220.

Antonov, J., Locarnini, R., Boyer, T., Mishonov, A., Garcia, H., 2006. World Ocean Atlas 2005 Volume 2: Salinity. NOAA Atlas NESDIS 62, U.S. Government Printing Office, Washington, D.C.

Barbosa Aguiar, A.C., Peliz, A.J., Cordeiro Pires, A., Le Cann, B., 2011. Zonal structure of the mean flow and eddies in the Azores Current system. J. Geophys. Res. 116. doi:10.1029/2010JC006538.

Bower, A., Serra, N., Ambar, I., 2002. Structure of the Mediterranean undercurrent and Mediterranean water spreading around the southwestern Iberian Peninsula. J. Geophys. Res. 107, C10,3161. doi:10.1029/2001JC001007.

Bower, A.S., Armi, L., Ambar, I., 1997. Lagrangian observations of Meddy formation during a Mediterranean undercurrent seeding experiment. J. Physical Oceanogr. 27, 2545-2575.

Carton, X., Chérubin, L., Paillet, J., Morel, Y., Serpette, A., Le Cann, B., 2002. Meddy coupling with a deep cyclone in the Gulf of Cadiz. J. Marine Sys. 32, 13-42.

Carton, X., Daniault, N., Alves, J., Chérubin, L., Ambar, I., 2010. Meddy dynamics and interaction with neighboring eddies southwest of Portugal: Observations and modeling. J. Geophys. Res. 115, C06017. doi:10.1029/2009JC005646.

Cenedese, C., 2002. Laboratory experiments on mesoscale vortices colliding with a seamount. J. Geophys. Res. 107, C6-3053. doi:10.1029/2000JC000599.

Chérubin, L., Carton, X., Dritschel, D., 2007. Vortex dipole formation by baroclinic instability of boundary currents. J. Physical Oceanogr. 37, 16611677 .

Chérubin, L., Carton, X., Paillet, J., Morel, Y., Serpette, A., 2000. Instability of the Mediterranean water undercurrents southwest of Portugal: effects of baroclinicity and of topography. Oceanologica Acta 23, 551-573. 
da Silva, A., Young, C.C., Levitus, S., 1994. Atlas of Surface Marine Data 1994, Volume 1: Algorithms and Procedures. NOAA Atlas NESDIS 6. U.S. Department of Commerce. Washington, D.C.

D'Asaro, E.A., 1988. Generation of submesoscale vortices: A new mechanism. J. Geophys. Res. 93, 6685-6693.

Demidov, A.N., Filyushkin, B.N., Kozhelupova, N.G., 2012. Detection of Mediterranean Lenses in the Atlantic Ocean by Profilers of the Argo Project. Oceanology 52, 171-180. doi:10.1134/S0001437012020038.

Dong, C., Lin, X., Liu, Y., Nencioli, F., Guani, Y., Chao, Y., Dickey, T., McWilliams, J., 2012. Three-Dimensional Eddy Analysis in the Southern California Bight. J. Geophys. Res. 117, C00H14. doi:10.1029/2011JC007354.

Drillet, Y., Bourdallé-Badie, R., Siefridt, L., Le Provost, C., 2005. Meddies in the Mercator North Atlantic and Mediterranean Sea eddy-resolving model. J. Geophys. Res. 110, C03016. doi:10.1029/2003JC002170.

Duarte, R., Carton, X., Capet, X., Cherubin, L.M., 2011. Trapped instability and vortex formation by an unstable coastal current. Reg. Chaotic Dyn. $16,577-601$.

Hedström, K.S., 2009. Technical Manual for a Coupled Sea-Ice/Ocean Circulation Model (Version 3). Technical report. Artic Region Supercomputing Center, University of Alaska Fairbanks.

Jungclaus, J., Mellor, G., 2000. A three-dimensional model study of the Mediterranean outflow. J. Marine Sys. 24, 41-66.

Kida, S., Price, J.F., Jiayan, Y., 2008. The Upper-Oceanic Response to Overflows: A Mechanism for the Azores Current. J. Physical Oceanogr. 38, 880-895. doi:10.1175/2007JPO3750.1.

Lamas, L., Peliz, A., Ambar, I., Barbosa Aguiar, A., Maximenko, N., TelesMachado, A., 2010. Evidence of time-mean cyclonic cell southwest of Iberian Peninsula: The Mediterranean Outflow-driven $\beta$-plume? Geophys. Res. Lett. 37. doi:10.1029/2010g1043339. 
Large, W., McWilliams, J., Doney, S., 1994. Oceanic vertical mixing: A Review and model with a nonlocal boundary layer parameterization. Reviews of Geophysics 32, 363-403.

Locarnini, R., Mishonov, A., Antonov, J., Boyer, T., Garcia, H., 2006. World Ocean Atlas 2005 Volume 1: Temperature. NOAA Atlas NESDIS 61, U.S. Government Printing Office, Washington, D.C.

Marchesiello, P., Debreu, L., Couvelard, X., 2009. Spurious diapycnal mixing in terrain-following coordinate models: The problem and a solution. Ocean Modelling 26, 156 - 169. doi:10.1016/j.ocemod.2008.09.004.

Marchesiello, P., McWilliams, J.C., Shchepetkin, A.F., 2001. Open boundary conditions for long-term integration of regional oceanic models. Ocean Modelling 3, 1-20.

Ménesguen, C., Hua, B.L., Carton, X., Klingelhoefer, F., Schnurle, P., Reichert, C., 2012. Arms winding around a meddy seen in seismic reflection data close to the Morocco coastline. Geophys. Res. Lett. 39, L05604, 6pp. doi:10.1029/2011GL050798.

Nencioli, F., Dong, C., Dickey, T., Washburn, L., McWilliams, J., 2010. A vector geometry based eddy detection algorithm and its application to high-resolution numerical model products and high-frequency radar surface velocities in the southern California Bight. J. Atmos. Oceanic Tech. 27, 564-579. doi:10.11.1175/2009JTECHO725.1.

Paillet, J., Le Cann, B., Serpette, A., Morel, Y., Carton, X., 1999. Realtime tracking of a Galician meddy. Geophys. Res. Lett. 26, 1877-1880. doi:10.1029/2007JC004159.

Peliz, A., Boutov, D., Cardoso, R., Delgado, J., Soares, P., 2013. The gulf of cadiz-alboran sea sub-basin: Model setup, exchange and seasonal variability. Ocean Modelling 61, 49-67. doi:10.1016/j.ocemod.2012.10.007.

Peliz, A., Dubert, J., Marchesiello, P., Teles-Machado, A., 2007. Circulation in the Gulf of Cadiz: Model and mean flow structure. J. Geophys. Res. 112, C11015. doi:10.1029/2007JC004159. 
Peliz, A., Teles-Machado, A., Marchesiello, P., Dubert, J., Lafuente, J.G., 2009. Filament generation off the Strait of Gibraltar in response to Gap winds. Dynamics of Atmospheres and Oceans 46, 36-45. doi:10.1016/j.dynatmoce.2008.08.002.

Penven, P., Marchesiello, P., Debreu, L., Lefèvre, J., 2008. Software tools for pre- and post-processing of oceanic regional simulations. Environmental Modelling Software 3, 660-662. doi:10.1016/j.envsoft.2007.07.004.

Pichevin, T., Nof, D., 1996. The eddy cannon. Deep-Sea Res. I 43, 1475-1509.

Richardson, P.L., Bower, A., Zenk, W., 2000. A census of meddies tracked by floats. Progress in Oceanography 45, 209-250.

Richardson, P.L., McCartney, M.S., Maillardi, C., 1991. A search for meddies in historical data. Dynamics of Atmospheres and Oceans 15, 241-265.

Richardson, P.L., Tychensky, A., 1998. Meddy trajectories in the Canary Basin measured during the Semaphore Experiment, 1993-1995. J. Geophys. Res. 103, C11, 25029-25045.

Richardson, P.L., Walsh, D., Armi, L., Schroder, M., Price, J., 1989. Tracking three meddies with SOFAR floats. J. Physical Oceanogr. 19, 371-383.

Sanz, J.L., Acosta, J., Esteras, M., Herranz, P., Palomo, C., Sandoval, N., 1991. Prospección geofísica del Estrecho de Gibraltar (Resultados del programa Hércules 1980-1983). Publicaciones especiales del Instituto Español de Oceanografía. Instituto Español de Oceanografía.

Serra, N., Ambar, I., 2002. Eddy generation in the Mediterranean Undercurrent. Deep-Sea Res. II 49, 4225-4243.

Serra, N., Ambar, I., Käse, R., 2005. Observations and numerical modelling of the Mediterranean outflow splitting and eddy generation. DeepSea Res. II 52, 383-408.

Serra, N., Sadoux, S., Ambar, I., Renouard, D., 2002. Observations and laboratory modeling of meddy generation at Cape St. Vincent. J. Physical Oceanogr. 32, 3-25. doi:10.1175/15200485(2002)032¡0003:OALMOM¿2.0.CO;2. 
Shapiro, G.I., Meschanov, S.L., 1996. Spreading pattern and mesoscale structure of Mediterranean outflow in the Iberian Basin estimated from historical data. J. Marine Sys. 7, 337-348.

Shchepetkin, A., McWilliams, J., 2003. A method for computing horizontal pressure-gradient force in an oceanic model with a nonaligned vertical coordinate. J. Geophys. Res. 108, C3, 35-1.

Shchepetkin, A.F., McWilliams, J.C., 2005. The regional oceanic modeling system (ROMS): a split-explicit, free-surface, topography-followingcoordinate oceanic model. Ocean Modelling 9, 347-404.

Smith, W., Sandwell, D., 1997. Global Sea Floor Topography from Satellite Altimetry and Ship Depth Soundings. Science 277, 1956-1962. doi:10.1126/science.277.5334.1956.

Zenk, W., Schultz-Tokos, K., Boebel, O., 1992. New observations of meddy movement south of Tejo plateau. Geophys. Res. Lett. 19, 2389-2392. 